\title{
A QUESTÃO 15 DO LIVRO IX DAS QUAESTIONES SUPER LIBROS METAPHYSICORUM ARISTOTELIS de Duns Scotus: Introdução, Estrutura e Tradução*
}

Roberto Hofmeister Pich**

\section{Introdução}

I. As Quaestiones super libros metaphysicorum Aristotelis ("Questões sobre os livros da Metafísica de Aristóteles") foram editadas criticamente em 1997, por uma equipe de especialistas do Franciscan Institute, da Universidade São Boaventura (St. Bonaventure, N. Y.). No quadro atual da pesquisa e da edição das obras de João Duns Scotus que chegaram até os dias de hoje, as Quaestiones compõem os volumes III e IV ${ }^{1}$ dos cinco que perfazem os escritos filosóficos (a Opera Philosophica) do Doutor Sutil, basicamente, aqueles em que o autor se dedica de modo explícito ao comentário e/ou à reflexão sistemática sobre temas presentes nas obras aristotélicas homônimas, ${ }^{2}$ conhecidas por Scotus, como para a maioria dos intelectuais medievais dos séculos 13 e 14, somente nas traduções para o latim.

II. Transmitidas de modo desordenado, embora, em termos gerais, ainda com 0 conteúdo bastante acessível, ${ }^{3}$ as Questões, hoje, não são mais simplesmente datadas

* Parte significativa da pesquisa que deu origem a este estudo foi feita durante período de pósdoutoramento, na Universidade de Bonn e no Albertus-Magnus-Institut, Alemanha, com o apoio da Alexander von Humboldt-Stiftung. Agradeço, pois, a essas instituições pelo inestimável apoio acadêmico, logístico e financeiro.

** Doutor em Filosofia, professor do Programa de Pós-Graduação em Filosofia da PUCRS.

1 Cf. as "Referências bibliográficas" abaixo.

2 Cf. L. A. De Boni, Sobre a vida e a obra de João Duns Scotus, in: Patristica et Mediaevalia, p. 62-63. Cf. também Th. Williams, The Works of John Duns Scotus, in: http://www.nd.edu/ wwillia5/dunsscotus/ works/html, consultado em 14.05.2008.

3 Cf. R. Andrews et alii, Introduction, in: R. Andrews et alii (eds.), Ioannis Duns Scoti Opera Philosophica III - Quaestiones super libros metaphysicorum Aristotelis Libri I-V, p. xxxii-xxxvii. 
no início da carreira de Scotus; antes, não se pode reivindicar uma única data aproximada para a obra toda. A convicção central é que as Questões foram tanto compostas quanto revisadas ao longo de um extenso período da vida acadêmica de Scotus. ${ }^{4}$ Assim, tanto parece correto que as questões sobre os Livros I-V são juvenis, ou, nesse caso, anteriores à Lectura (1298-1299), como há convencimento de que as questões sobre os Livros VII-IX ganharam num período tardio a forma agora conhecida (quiçá após 1302, isto é, já na fase de composição da Reportatio parisiensis). ${ }^{5}$

III. A investigação, por Scotus, dos Livros I-IX, é estruturada por meio de muitas questões. É bem conhecido que a típica "questão" escolástica é tripartida, iniciando com (i) uma breve apresentação dos argumentos pró e contra, seguindo-se (ii) o corpo da questão, no qual o autor explicita a sua análise dos problemas envolvidos e oferece a sua resposta, findando com (iii) a(s) resposta(s) aos argumentos lançados no começo. ${ }^{6}$ Amplamente, na obra textual scotista, o corpus é a parte mais importante. Afinal, ali o mestre não apresenta somente a solução da quaestio, mas revela o mundo intelectual ao qual pertence, acusando os debates do seu tempo e as suas características argumentativas como autor. É, portanto, inteiramente adequado constatar que, no corpo da questão, novos argumentos pró e contra costumam aparecer, de forma que "este método dialético parece refletir como o próprio Scotus analisou um assunto, indicando que, para ele ao menos, a questão escolástica ainda é um meio vivo de expressão".?

IV. Não sendo um comentário ao Livro IX da Metafísica, mas permanecendo próximo aos seus temas e problemas filosóficos, o liber nonus das Quaestiones in libros metaphysicorum Aristotelis, de João Duns Scotus, enfoca o conceito de "potência" (potentia). São essas as suas questões:8 (1-2) "Se potência e ato se opõem"; "Se ato e potência se opõem relativamente"; (3-4) "Se a potência é dividida suficientemente pelo Filósofo"; "Se a potência ativa é bem descrita"; (5) "Se a potência inclui essencialmente uma relação"; (6) "Se a potência ativa está fundada em todo ente"; (7) "Se a relação da potência ativa está fundada imediatamente na substância";

4 Ibid., p. xlii-xlvi.

5 Cf. Th. Williams, Introduction - The Life and Works of John Duns the Scot, in: Th. Williams (ed.), The Cambridge Companion to Duns Scotus, p. 8-9. Além disso, chegou-se a ter convicção de que uma Expositio sobre os Livros da Metaphysica de Aristóteles, escrita por Scotus, fora definitivamente perdida. Há pouco mais de uma década, porém, o manuscrito que a contém foi descoberto por Giorgio Pini, que trabalha na sua edição; cf. Th. Williams, The Works of John Duns Scotus, op. cit., consultado em 14.05.2008. É certo que L. Wadding (Lyon, 1639) editou uma Expositio [literalis] super libros Metaphysicorum Aristotelis que, na realidade, é da autoria de Antônio André. Cf. também R. Andrews et alii, Introduction, in: R. Andrews et alii (eds.), op. cit., p. xxxix-.

6 Cf. A. B. Wolter, Introduction, in: John Duns Scotus, A Treatise on Potency and Act - Questions on the Metaphysics of Aristotle Book IX, p. 12-13.

7 Ibid., p. 13.

8 Cf. Duns Scotus, Opera Philosophica IV - Quaestiones super libros Metaphysicorum Aristotelis, ed. by R. Andrews et alii, St. Bonaventure, Franciscan Institute Publications, 1997, IX q. 1-15, p. 507-699. 
(8) "Se alguma qualidade da primeira espécie é uma potência ativa"; (9) "Se a potência ativa pode ter termo em todo e qualquer [ente]"; (10) "Se a potência passiva é em todo e qualquer ente"; (11) "Se a potência passiva pode ter termo em qualquer ente causado"; (12) "Se a potência passiva é dividida em natural, obediencial (ou sobrenatural) e violenta"; (13) "Se a potência passiva é dividida em da qual [de qua] (ou a partir da qual [ex qua]) e na qual [in qua]"; (14) "Se algo pode ser movido por si mesmo"; (15) "Se a diferença assinalada por Aristóteles entre as potências racionais e irracionais é conveniente".

V. A proximidade do Livro IX das Quaestiones com a Metafísica de Aristóteles ou, mais especificamente, com o Livro IX da Metafísica, sugere um olhar retrospectivo. No que é hoje tido como o terceiro Livro dos "Livros da substância" ou "Livros intermediários" (isto é, Metafísica VII-IX), Aristóteles se dedicara ao par conceitual "ato" e "potência". No contexto, pois, Aristóteles considera diversos candidatos para a realidade da "substância" ou "primeira substância" (ousia, prôtê ousia; VII 1-2), o conceito central da sua ontologia madura - a "ciência do ente enquanto ente" (cf. Metafísica IV 1, 1003a21-22) e em cuja definição "ente" está, ao final, por "substância" (Metafísica VII 4, 1029b11-1030b13). Buscando justamente no Livro VII uma teoria unificada da substância, Aristóteles defende que o objeto primeiro da metafísica, aquele que define a Filosofia Primeira ao preencher os critérios de ente primário, ${ }^{9}$ não é o "universal" (katholou), o "gênero" (genos) ou o "substrato" (hypokeimenon; VII 3), tampouco a "matéria" (hylê) ou o "composto" de matéria e forma (synholon) na ótica dos processos de mudança, geração e corrupção (VII 7-9), mas a "essência" (to ti ên einai; VII 3, 1024b34ss. e VII 4) ${ }^{10}$ ou, ainda, a "forma" (eidos) como a "primeira substância" (VII 17), ${ }^{11}$ ali onde aquela noção é retomada como sujeito particular com propriedades objetivas (um "este" ou tode ti) e, ao que tudo indica com maior "prioridade", como "qüididade" (ti estin), tal como essa é expressada em predicados específicos e/ou de definição específica. ${ }^{12}$

VI. Se o Livro VIII acusa uma diferença sensível em relação ao Livro VII, dado que se trata naquele de garantir de modo conseqüente a independência da "forma" ou "primeira substância" junto à investigação de substâncias particulares perceptíveis

9 Cf. Ch. Rapp, Substanz als vorrangig Seiendes (Z 1), in: Ch. Rapp, (Hrsg.), Aristoteles Metaphysik: Die Substanzbücher (Z, H, $\Theta)$, p. 34ss.

10 Cf. Ch. Rapp, Einleitung: Die Substanzbücher der Metaphysik, in: Ch. Rapp (Hrsg.), Aristoteles Metaphysik: Die Substanzbücher (Z, H, $\Theta$ ), p. 10-11. Sobre a inovadora construção e o ganho conceitual do "to ti ên einai" de Aristóteles, cf. o brilhante estudo de H. Weidemann, Zum Begriff des ti ên einai und zum Verständnis von Met. Z 4, 1029b22-1030a6), in: Ch. Rapp. (Hrsg.), Aristoteles Metaphysik: Die Substanzbücher (Z, H, $\Theta)$, p. 75-103.

11 Cf. D. Morrison, Substance as Cause: Metaphysics Z 17, in: Ch. Rapp (Hrsg.), Aristoteles Metaphysik: Die Substanzbücher (Z, H, @), p. 193-196, 199-201.

12 Cf. Ch. Rapp, Einleitung: Die Substanzbücher der Metaphysik, in: Ch. Rapp (Hrsg.), op. cit., p. 12-14; idem, Substanz als vorrangig Seiendes (Z 1), in: Ch. Rapp, (Hrsg.), op. cit., p. 37ss. Cf. também O. Höffe, Aristoteles, p. 172-177. 
aos sentidos (consideradas, pois, como concretos compostos ou "synhola"), notando-se a necessidade de estudar as conseqüências de a indeterminação do material e do singular ficar inseparada da "eidos" ou da substância qua composição e, em geral, o papel da matéria nas substâncias singulares que passam por processos de mudança, ${ }^{13}$ lê-se ali a agenda de fundamentação da "potencialidade" e da "atualidade" da realidade unificada da substância concreta ${ }^{14}$ - a ser cumprida no Livro IX. O Livro IX constitui um tratado sobre dynamis e energeia. Grosso modo, o primeiro passo, nos capítulos 1-5, é o tratamento da "potência" (dynamis), passível de análise (i) como princípio da mudança na realidade (IX 1), (ii) como possível lógico e ontológico (IX 3-4) e (iii) segundo a distinção entre potência racional e potência irracional (IX 2 e 5); o segundo passo, efetuado nos capítulos 6-9, é a análise da "atualidade" (energeia) e, em contraste, da "possibilidade" em sentido metafísico: como princípios do ser e do não-ser (IX 6), no modo como o material-potencial é algo real (IX 7), nos termos em que a atualidade tem primazia com respeito à potencialidade (IX 8-9). Finalmente, em Metafísica IX 10, Aristóteles retorna à investigação tripartida do "ente" em sentido próprio - que fora anunciada em Metafísica V 7 -, ou seja, investiga a "verdade" e a "falsidade" do ente e do não-ente. ${ }^{15}$

VII. Como seria de se esperar, a concentração dada por Scotus ao conceito de "potência", no Livro IX das suas Quaestiones in libros metaphysicorum Aristotelis, mantém a aliança filosófica daquele conceito com a noção de "ato": é uma lição antiga dos intérpretes de Aristóteles insistir que a atualidade é, por definição, logicamente anterior à potencialidade, tal como "poder ser $B$ " é uma idéia mais complexa do que "ser $B$ ", além de que $A$ só é potencialmente $B$ se pode tornar-se atualmente $B$, se é uma atualidade que "pode ser" $B$; ora, se tornar-se atualmente $B$ só se pode passar, para $A$, a partir da ação do que já é atual, a potencialidade que $A$ tem de ser $B$ tem de pressupor uma certa atualidade. ${ }^{16} O$ próprio Scotus, tematizando na Questão 2 a oposição "de modo relativo" (relative) e "não-mutuamente" (non mutuo) entre potência e ato, ao explicitar então o que se supõe com os nomes "potência" e "ato", adverte que potentia "diz uma ordem ao ato, e por esse modo é essencialmente uma relação com o ato", ao passo que "a razão do ato [ratio actus] é absoluta", de acordo com o que mostrara Aristóteles em Metafísica IX c. 4, 1048a

13 Como entender o sentido da "matéria" ou causa material, na teoria aristotélica da substância, a saber, ao mesmo tempo como aspecto da realidade substancial particular subordinado à forma - e não mero "não-ente" - e como mero indeterminado e mero potencial, permanece um dos principais problemas da interpretação contemporânea da Metafísica de Aristóteles; cf. H. Seidl, Einleitung, in: H. Seidl (Hrsg.), Aristoteles' Metaphysik - Erster Halbband (Bücher I-VI), p. iii.

14 Cf. Ch. Rapp, Einleitung: Die Substanzbücher der Metaphysik, in: Ch. Rapp (Hrsg.), op. cit., p. 14-17.

15 A estrutura e o conteúdo do Livro IX da Metafísica, em cada um dos seus capítulos, é belamente apresentada por H. Seidl, Kommentar, in: H. Seidl (Hrsg.), Aristoteles' Metaphysik - Zweiter Halbband: Bücher VII(Z)-XIV(N), p. 460-496.

16 Cf. D. Ross, Aristóteles, p. 182-183; cf. ainda A. B. Wolter, Introduction, in: John Duns Scotus, op.cit., p. 13. 
31-32. ${ }^{17}$ Para todos os efeitos, A. B. Wolter, que traduziu todo o Livro IX das Questões, numa edição bilíngüe latim-inglês, chamou atenção para o fato de que ali se encontra a mais extensa abordagem scotista das noções de "potencialidade e atualidade" (potentiality and actuality) - que, no texto scotista, aparecem, basicamente, nas formas "potentia" (para dynamis) e "actus" (para energeia e também para entelecheia, cuja versão latina mais exata é, no entanto, "actualitas"). Nas edições Wadding-Vivès, as questões do Livro IX foram introduzidas com breves passagens de Aristóteles em latim. No caso da Questão 15, o trecho é Metaphysica IX 2, 1046b2-6. ${ }^{18}$ Há convicção da parte dos editores que Scotus, para os seus tópicos, nem fez uso da Translatio anonyma da Metafísica (preferencialmente usada no aparato da atual edição crítica) nem da Translatio Moerbeccana, mas de uma versão latina de outra mão, hoje não identificada. ${ }^{19}$

VIII. O Livro IX é, a propósito, o último Livro das Questões propostas por Scotus acerca da Metafísica de Aristóteles. Voltando ao tema do seu lugar dentro da biografia intelectual do autor, A. B. Wolter viu nele um franco contraste de acabamento com os demais oito Livros: o Livro IX bem poderia ser visto como uma "ordinatio" ou um texto revisado definitivamente, apto a uma publicação independente. ${ }^{20}$ Nesse Livro, observam-se tanto (a) traços de composição e revisão que se estendem por um longo período de tempo quanto (b) familiaridades temáticas que apontam para uma composição que só pode ter tido fim numa fase tardia da carreira de Scotus ${ }^{21}$ acrescento, como exemplos, o poder simultâneo para opostos por parte da vontade, ao agir (cf. na tradução n. 20-34, 54-62, 63-65), familiar à Lectura, I, d. 39, q. 1-5 e à Reportatio parisiensis, I, d. 39-40, q. 1-3,22 e a associação do contingente ao conhecimento de proposições imediatas ou per se (cf. na tradução n. 20-34), familiar às discussões epistemológicas da Ordinatio, em diversas passagens. ${ }^{23}$ Se partes do liber nonus receberam de fato um acabamento tardio, as questões 14-15 se incluem entre elas.

17 Cf. Duns Scotus, Quaest. sup. libr. Metaph. Arist., IX, q. 1-2 n. 23: “(...), nam supponendo significatum nominis, patet quod potentia sic sumpta dicit ordinem ad actum, et iste ordo essentialiter est respectus ad actum. (...). Sed hoc non est e converso, quia ratio actus est absoluta, ut probatum est ex intentione PHILOSOPHI".

18 Cf. A. B. Wolter, Introduction, in: John Duns Scotus, op. cit., p. 11-12, nota 4.

19 Cf. R. Andrews et alii, Introduction, in: R. Andrews et alii (eds.), op. cit., p. xlviii-l.

20 Cf. A. B. Wolter, Preface, in: John Duns Scotus, A Treatise on Potency and Act - Questions on the Metaphysics of Aristotle Book IX, p. 9.

21 Sobre diversas passagens dos Livros VII, VIII e IX das Questões que contêm possíveis paralelos com a Lectura, Ordinatio e De primo principio, cf. R. Andrews et alii, Introduction, in: R. Andrews et alii (eds.), op. cit., p. xlii-xlvi, também notas 88-99.

22 Cf. Duns Scotus, Lectura, I, d. 39, q. 1-5, n. 31-68 (ed. Vat.: XVII, 488-502); Reportatio examinata, I, d. 39-40, q. 1-3, n. 25-59 (ed. Söder, 2005: 76-98).

23 Cf. Duns Scotus, Ordinatio, prol., p. 3, q. 1-3, n. 169 (ed. Vat.: I, 112-113); I, d. 3, p. 1, q. 4, n. 238-239 (ed. Vat.: III, 144-146); I, d. 8, p. 2, q. un., n. 299-300 (IV, 324-325). 
IX. Foi notado também por A. B. Wolter que, se nas questões 1-13, Scotus, ao discutir a natureza e as características de potência e ato, dirige-se quase exclusivamente ao primeiro capítulo do Livro IX da Metafísica de Aristóteles - em tese centrado nos mais importantes significados de "dynamis", em particular como princípio ativo e como princípio passivo de movimento-mudança -, as questões 14 e 15, de longe as mais extensas do Livro IX de Scotus, "são aplicações da concepção scotista de potência como um princípio". ${ }^{24}$ Assim, é tanto uma passagem de Metafísica IX 1, propondo que uma coisa qua unidade orgânica não pode ser objeto de ação por si mesma como princípio de mudança, que motiva a questão 14 ("Se algo pode ser movido por si mesmo"), quanto uma passagem no começo de Metafísica IX 2, "(...) [é preciso] claramente que algumas das potências sejam irracionais [alogoi], outras com a razão [meta logou] (...)", que impulsiona a questão 15 ("Se a diferença assinalada por Aristóteles entre as potências racionais e irracionais é conveniente"). O ponto de disputa, para Scotus, passa a ser se, ali, a distinção entre potências semrazão e com-razão descreve adequadamente todas as potências ativas ou princípios ativos, vindo a mostrar que, se o critério aristotélico de distinção é interpretado à risca, só a "vontade" (voluntas) é uma "potência racional" (potentia rationalis), e só em sentido secundário outras potências ou faculdades, sob controle voluntário, podem ser chamadas de "racionais". Para A. B. Wolter, finalmente, a Questão 14 e a Questão 15 acabam por discutir "a natureza das duas formas básicas da potênca metafísica", a saber, como um "modo de ser"25 (tal como quando se diz "algo é potencialmente" ou "em potência", em oposição, no mesmo ente, ao modo de ser atual, tal como "algo em si possível existe atualmente") e enquanto "princípio" ou "função". ${ }^{26}$

X. O segundo significado, primário na análise aristotélica da dynamis, ${ }^{27}$ da potência como "princípio", portanto, permite dizer que aquilo que é potencial pode estar atualmente "funcionando", muito embora não precise estar atualmente funcionando.

24 Cf. A. B. Wolter, Introduction, in: John Duns Scotus, op. cit., p. 14.

25 H. Weidemann, dynamis/Vermögen, Möglichkeit, in: O. Höffe (Hrsg.), Aristoteles-Lexikon, p. 142, nota que, em Metafísica, IX, 6, 1048a32-37, a chave para esse significado se encontra menos numa definição e mais num olhar análogo, ali onde são comparadas relações mutuamente análogas entre algo que em potencialidade e algo que em atualidade é $F$, entre algo que em potencialidade e algo que em atualidade é $G$, e assim por diante: de duas coisas uma é segundo a potencialidade e a outra é segundo a atualidade ali onde uma se comporta para com a outra tal como alguém que possui a técnica de construção com respeito àquele que realmente está construindo.

26 Cf. A. B. Wolter, Introduction, in: John Duns Scotus, op. cit., p. 14. Cf. Duns Scotus, Quaest. sup. libr. Metaph. Arist., IX, q. 1-2, n. 14, p. 512: "Ad solutiones istarum quaestionum oportet distinguere de potentia. Uno modo potentia dicit modum quendam entis. Alio modo specialiter importat rationem principii". Cf. id. ibid., IX, q. 1-2, n. 16, p. 512-513: "Hic ergo videndum est de potentia communius accepta, videlicet ut importat modum quendam entis in se sine ratione principii. (...). Et ideo propter brevitatem in sermone potest dici 'potentia metaphysica'". Cf. ainda J. Boler, The Ontological Commitment of Scotus's Account of Potency in his Questions on the Metaphysics, Book IX, in: L. Honnefelder; M. Dreyer; R. Wood (eds.), John Duns Scotus - Metaphysics and Ethics, p. 146s., 147ss., 153ss. Para J. Boler, cf. ibid., p. 147, Scotus dedica as Questões 1-2 ao tema do "modo do ente" e as Questões 3-15 ao tópico da potência como "princípio". Quanto ao tema do "modo do ente", cf. A. Santogrossi, Duns Scotus on Potency Opposed to Act in Questions on the Metaphysics, IX, in: The American Catholic Philosophycal Quarterly, p. 55-76.

27 Cf. por exemplo, M.-Th. Liske, Inwieweit sind Vermögen intrinsische dispositionelle Eigenschaften?

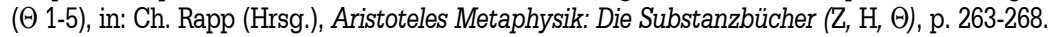


Um princípio não é menos em realidade quando "principia" ou "opera como princípio em ato" ("actu principiat") do que quando "não principia" ou "não opera como princípio, mas pode operar como princípio"; nesses termos, já na solução das Questões 1 e 2 Scotus dirá que a potência como princípio, pela sua razão mesma, "não está em oposição ao ato". ${ }^{28}$ A. B. Wolter ressalta que, para Scotus, "potência" é fonte originadora ou "causa" do ser - reconhecendo a eqüivocidade desse último termo, que se presta a duas causas intrínsecas e a duas extrínsecas. ${ }^{29}$ Diante disso, aplicável à potência como princípio é sobretudo a "causa eficiente", redutível ou identificável com a forma e que é chamada de "potência ativa", por seu papel como fonte de atividade e produtividade de uma dada substância na natureza. Por semelhante modo, aplicável à potência como princípio é também a "causa material", 30 que vem a ser chamada de "potência passiva", uma vez que é a razão pela qual uma dada natureza pode ser receptiva ou bem da sua própria ação imanente ou daquelas ações de outro(s) que lhe afetam. ${ }^{31}$ Essa divisão bem se associa ao significado básico da "dynamis" aristotélica, em que a potência como princípio de uma substância é tal que ele opera mudança em outra coisa ou na substância mesma como se fosse outra coisa - assim se mostra a potência do médico em causar modificação no organismo do paciente, no intuito de que ele seja curado (Metafísica, V, 12, 1020a1-5; 1019a 15-18; IX, 1, 1046a11). Naturalmente, corresponde à potência ativa de efetuar mudança, por parte daquilo em que a mudança ocorre, uma potência passiva ou de capacidade de sofrer a ação - em que a caracterização mútua a partir de casos de mudanças possíveis leva à denominação dessas como "potências cinéticas" (Metafísica, IX, 1, 1046a11-13; IX, 6 1048a25), ${ }^{32}$ que, não obstante isso, inserem-se na consideração do metafísico. ${ }^{33}$

28 Cf. Duns Scotus, Quaest. sup. libr. Metaph. Arist., IX, q. 1-2, n. 15, p. 512: "Hic enim patet quod non est de illa potentia difficultas, quia non minus realiter est aliquid principium quando actu principiat quam quando non principiat, sed potest principiare. Et ita pro solutione istarum duarum quaestionum patet quod potentia, ut est principium, de ratione sui non opponitur actui".

29 Cf. A. B. Wolter, Introduction, in: John Duns Scotus, op. cit., p. 15.

30 Cf. Duns Scotus, Quaest. sup. libr. Metaph. Arist., IX, q. 3-4, n. 6, p. 536: "(..); ergo quattuor debent esse potentiae correspondentes quattuor causis. Omnes autem hic positae videntur correspondere duabus, scilicet agenti et materiali". Cf. ibid., IX, q. 3-4, n. 24, p. 544: "Principium autem potentiale respectu principiati tantum potest esse duplex, scilicet efficiens et materia. Forma enim numquam praecedit compositum; nec per ipsum [principium quod est forma], tamquam per principium potentiale, posset compositum esse in potentia. Similiter, nec finis quantum ad esse in re. Et ideo forte, ut 'potentia' significat principium, non est impositum generaliter omni principio sive causae, sed tantum principio activo quod est quo efficiens potest efficere, et principio passivo quod est quo ex aliquo potest fieri aliquid; et per utrumque istorum principiatum est in potentia".

31 Cf. A. B. Wolter, Introduction, in: John Duns Scotus, op. cit., p. 15-16. Em ibid., p. 17, A. B. Wolter traz uma descrição geral dos vários sentidos e subdivisões de potência metafísica que Scotus trata no seu Livro IX. A descrição "é baseada em se a oposição de potência e ato é radical, sendo um atributo disjuntivo do ente, ou se a atualidade não é tão oposta que a potência e a sua atualidade não possam coexistir" (p. 16).

32 Cf. H. Weidemann, dynamis / Vermögen, Möglichkeit, in: O. Höffe (Hrsg.), op. cit., p. 140.

33 Cf. ainda Duns Scotus, Quaest. sup. libr. Metaph. Arist., IX, q. 3-4, n. 31, p. 550: "Est autem potentia activa, secundum eius unam significationem, metaphysique loquendo, principium agendi agibile; secundum aliam, principium actuandi actuabile. Potentia vero passiva, secundum unam eius significationem, est principium ex quo aliquid potest materiari; secundum aliam est principium actuandi passive ab actu activo; secundum tertiam est principium actuabile sive informabile ab actu, sive a principio actuali". 
XI. Há que se reconhecer que, na Questão 15, Scotus defende - com muito mais consistência teórica - algo que Henrique de Gand, antes dele, tinha defendido: ${ }^{34}$ a tese de que é a vontade a potência que é estritamente racional, em verdade, a única faculdade humana plenamente racional. ${ }^{35}$ Ali, Scotus pretende fundamentar essa conclusão num critério aristotélico que tipifica o exercício de distinguir faculdades racionais e irracionais. Esse critério reza que as potências racionais ou "que são com a razão" são "de efeitos contrários", enquanto as potências irracionais são "de um único efeito" (cf. Metafísica IX 2, 1046b2-6). ${ }^{36}$ Ainda assim, como deve ser entendido este critério e a distinção conseqüente, ao se tratar da potência como princípio e como causa - na Questão 15, sem dúvida, carregando precipuamente 0 sentido de princípio ativo ou causa eficiente? Afinal, admitir, talvez não tanto a intenção, mas sobretudo a letra de Aristóteles exigirá descrever atentamente 0 intelecto e a vontade como princípios de operação, ${ }^{37}$ em parte as suas relações mútuas - passos esses que só podem ser feitos a partir da análise cuidadosa ou da intuição dos atos desses princípios de operação $0^{38}$ - e, ao final, mostrar a irredutibilidade da vontade quando do ato volitivo como poder (simultâneo) para opostos e intrínseca capacidade de autodeterminação. Fazendo uso de uma nova terminologia, cabe insistir de modo consistente na diferença entre o operar natural e o operar livre, ${ }^{39}$ mostrando que a distinção aristotélica só é promissora se for remetida à premissa de que todo e qualquer princípio de ação é ou bem "natural" ou "livre" (cf. abaixo IX, q. 15, n. 20-22). ${ }^{40}$

34 Esse ponto está atestado no próprio aparato da Quaestio 15 do Livro IX de Scotus; cf. a remissão explícita ao Quodlibet, XI, q. 7, de Henrique de Gand, no n. 16 e na nota 89, abaixo. A influência de Henrique de Gand sobre a abordagem, por Scotus, da noção aristotélica de potência racional não foi tocada no estudo de G. Wilson, The Presence of Henry of Ghent in Scotus's Quaestiones super libros metaphysicorum, in: L. Honnefelder; M. Dreyer; R. Wood (eds.), John Duns Scotus - Metaphysics and Ethics, p. 107-124 (em especial, p. 121-122).

35 Independentemente disso, Henrique de Gand adotou uma concepção antes "estatística" da modalidade ou da possibilidade metafísica; Scotus, mesmo se nisso o seguiu por algum tempo, depois defendeu em definitivo uma concepção "estrutural" da modalidade ou, no caso, de possibilidades "sincrônicas" para a contingência; cf. sobre isso, focando a teoria do "possível", S. P. Marrone, Revisiting Duns Scotus and Henry of Ghent on Modality, in: L. Honnefelder; M. Dreyer; R. Wood (eds.), John Duns Scotus - Metaphysics and Ethics, p. 175-189.

36 Cf. A. B. Wolter, Commentary, in: John Duns Scotus, A Treatise on Potency and Act - Questions on the Metaphysics of Aristotle Book IX, p. 62.

37 Nesse, como em outros contextos, entre a alma e as potências do intelecto e da vontade há, para Scotus, somente uma distinção formal: ora, é a alma realmente, não as suas faculdades, que causa as ações mentais. R. Cross, Duns Scotus, p. 83-84, afirma que a alma tem potências, pelas quais realiza ações e operações. Que o "intelecto" e a "vontade" causam as suas próprias ações, isso pode ser reduzido a uma "conveniência semântica".

38 Cf. R. H. Pich, Vontade livre e contingência: sobre a análise scotista do ato volitivo, in: M. R. N. Costa e L. A. De Boni (Orgs.), A ética medieval face aos desafios da contemporaneidade, p. 412-414.

39 Cf., sobretudo, A. B. Wolter, Duns Scotus on the Will as Rational Potency, in: M. Mc. Adams (ed.), The Philosophical Theology of John Duns Scotus, p. 167s.

40 Cf. R. Vier, A essência da liberdade na doutrina de João Duns Escoto, in: A. Garcia (org.), Estudos de filosofia medieval - A obra de Raimundo Vier, Petrópolis/São Paulo/Curitiba, Editora Vozes/Universidade São Francisco/Editora UFPR, 1997, p. 22. 
XII. Mas, sendo a estrutura básica da noção de potência ativa essa que se anuncia, é evidente que o seu escopo é amplo: há potências ativas em todo o reino da natureza, cobrindo tanto princípios naturais irracionais, como o frio e o calor, quanto princípios racionais (cf. IX, q. 15, n. 1-7, 10), de início ligados por Aristóteles a alguma descrição de alma racional. Não é surpreendente que as potencialidades que são desprovidas de alma racional não podem senão agir por impulso de natureza ou instinto - não poderiam jamais ter uma vontade livre, excluindo-se de qualquer suposição razoável de potência para efeitos opostos sobre os quais ela "a partir de si tem poder" ou sobre os quais ela enquanto tal "atua" (cf. IX q. 15 n. 10-11). Ora, muito embora possam haver condições extrínsecas que adicionam àquilo que uma potência (causa) ativa produz, para a idéia estrita de potência racional em si causalidades efetivas adicionais à ação que a potência ativa produz a partir de si mesma têm de ficar fora de consideração. Diferentemente de uma potência racional, são fatores extrínsecos ao poder causal do princípio ativo da natureza que se chama "calor do sol", a saber, os materiais de distinta natureza que sofrem a ação, que explanam os efeitos contrários do calor (cf. IX q. 15 n. 5, 43 e 69): eles adicionam de si mesmos uma contribuição causal ao efeito que o princípio causal do calor do sol não pode fornecer ${ }^{41}$ Esse critério de consideração "de si" daquilo que as potências ativas são como princípios - e a partir disso do modo como podem ser divididas consistentemente - ganha síntese em IX, q. 15, n. 12, onde Scotus afirma que as potências ativas são uma "natureza absoluta", "o próprio fundamento de muitas relações", tal como a substância ou uma qualidade sua: elas não são relações. A. B. Wolter indica com precisão que, no sentido de sujeito-substância, a potência ativa é o principium quod e, por agir através das faculdades que tem, é um poder "pelo qual", um principium quo. Enfim, abstraindo do modo como, para o princípio racional para opostos que se quer encontrar, o intelecto ou a vontade atuam como causa eficiente, vale como idéia geral que só a alma racional no domínio sobre as suas ações voluntárias contaria como forma de vida ativa da natureza que dispõe de princípios de ação capazes de preencher o que Aristóteles enseja com a "potência racional". 42

XIII. Na maneira como Scotus estabelece um duplo sentido de "forma natural", no discurso aristotélico, em que o segundo sentido, uma "forma do intelecto", é um "princípio de assimilar opostos" (cf. IX, q. 15, n. 13-14), ele, ao criticá-la (cf. IX, q. 15, n. 15-19), acaba por ficar próximo ao que o texto aristotélico mesmo apresenta como a "potência racional" da distinção proposta: afinal, Aristóteles apresenta somente "o intelecto ou a sua ciência como potência racional". ${ }^{43} \mathrm{O}$ intelecto ou a razão tem poder para algo e para o seu oposto (ou um "oposto contrário", um enantion ou contrarium), diferentemente de todas as potências irracionais, que só podem produzir

41 Cf. A. B. Wolter, Commentary, in: John Duns Scotus, op. cit., p. 64.

42 Ibid., p. 63.

43 Ibid., p. 65-66. 
um efeito específico (ou um "oposto contraditório", um contradictorium). ${ }^{44}$ Assim, 0 racional se vê na ciência da medicina, visto que tem poder sobre a saúde e a doença - ainda que só acidentalmente tenha poder para o oposto daquilo sobre o que age, dado que o oposto, quando a potência age, é uma privação da coisa produzida (cf. IX, q. 15, n. 14, 19; Metafísica IX 2, 1046a36-1046b28). ${ }^{45}$ Como o faz Aristóteles, os comentários medievais por característica expandem bastante 0 âmbito das potências racionais respectivas, ou seja, as ciências ou as artes práticas - e também as ciências morais práticas tal como a prudência ${ }^{-46}$, as quais igualmente se voltam só acidentalmente ao oposto do objeto gerado.

XIV. Acerca da suficiência da distinção proposta por Aristóteles o Doutor Sutil decide na passagem IX, q. 15, n. 20-34 - que, como indica o subtítulo legítimo dado pelos editores, "sobre a diferença entre natureza e vontade", tira conseqüências da hipótese, reconhecida por Scotus na obra de Henrique de Gand no que tange a análise do "poder para contrários" (IX, q. 15, n. 16), de que o significado próprio do "posse" ou da "potentia ad contraria" real se encontra só na contingência ou liberdade da vontade. Scotus explora essa percepção, no contraste entre "livre" e "natural", para reinterpretar o "racional" e o "irracional" das potências ativas como princípios de operação (IX, q. 15, n. 22, 24). Na realidade, mesmo dentro do opus aristotélico (Física II, 5-6, 197a32-b13) Scotus contenta-se em identificar, além da diferença entre natureza (determinada a um efeito) e arte/ciência (não-determinada), a tonalidade certa do contraste, isto é, aquele entre "natureza" (natura) e "vontade" (voluntas). Afinal, essa divisão de maior poder explanatório seria, a saber, instanciada no contraste entre "acaso" (casus) segundo a "natureza" e a "fortuna" (fortuna) "segundo o propósito ou a vontade", que nada mais são do que expressões de causalidades acidentais de princípios ativos (IX q. 15 n. 23). ${ }^{47}$ Que é a vontade que se presta a um poder para contrários tão estritamente analisado que pode mesmo ser redutível à indeterminação "naquele instante" e "para aquele instante" em que age (IX q. 15 n. 59-60) - de modo que num tempo $t$ discreto de uma volição ela quer algo e pode querer o oposto contrário, ou seja, "não querer" (non velle) ou "desquerer" (nolle) (IX q. 15 n. 30) -, sendo ademais uma causação marcada por irredutibilidade explanatória (IX q. 15 n. 24-25), ${ }^{48}$ logicamente expressa, numa proposição descritiva, como

44 Cf. H. Weidemann, enantion / konträr entgegengesetzt, in: O. Höffe (Hrsg.), Aristoteles-Lexikon, p. 175-176; idem, antiphasis / Widerspruch, in: O. Höffe (Hrsg.), Aristoteles-Lexikon, p. 50-52.

45 Cf. também H. Seidl, Kommentar, in: H. Seidl (Hrsg.), op. cit., p. 463-464.

46 Cf. A. B. Wolter, Commentary, in: John Duns Scotus, op. cit., p. 64; C. González Ayesta, Introducción, in: Juan Duns Escoto, Naturaleza y voluntad, Quaestiones super libros Metaphysicorum Aristotelis, IX, q. 15, p. $16 \mathrm{~s}$.

47 Cf. também Duns Scotus, Quaestiones quodlibetales q. 16, n. [14] 40 (ed. Alluntis: 602-603).

48 É interessante comparar isso com a idéia de "indemonstrabilidade" epistêmica de algumas proposições contingentes (em analogia com o princípio de não-contradição), defendida por Scotus em Ordinatio I, d. 3, p. 1, q. 4, n. 238 (ed. Vat.: III, 145): "(...); et subdit: "Rationem quaerunt quorum non est ratio, demonstrationis enim principii non est demonstratio". Ergo per ipsum, ibi, 'non vigilare' est per se notum sicut principium demonstrationis; (...)". Aplicada a noção de "indemonstrabilidade" a proposições contingentes, o seu sentido mais preciso poderia ser o de "irredutibilidade causal"; cf. a explanação 
"proposição contingente imediata" ou "por si" (IX q. 15 n. 26, 28-29), ${ }_{1}^{49}$ isso não pode ser provado a priori do conhecimento da natureza da vontade. Porém, pode ser provado a posteriori - por experiência - na imediata constatação ou introspecção cognitiva de como se deixam ver as operações do querer. ${ }^{50}$

XV. Se é fútil buscar razões por que a vontade como princípio causal age como age ou contingentemente - visto que isso cai sempre de novo na indicação do tipo de potência ativa ou causa eficiente que ela é -, também é fútil buscar razões por que 0 intelecto como princípio causal age como age ou necessariamente, porque, diante de um mesmo argumento por constatação de irredutibilidade causal, o que opera tal como o intelecto está determinado, toda vez que opera, a um único efeito. A partir daí, é novamente fútil buscar razões posteriores por que a distinção mesma entre natureza e vontade é tal como é. ${ }^{51}$ Ora, também por recurso a evidências de constatação, o intelecto como princípio causal, quando comparado com os atos próprios que realiza, mostra causalidade determinada: é de si determinado a inteligir, não tendo, ao operar, nem poder sobre o inteligir e o não-inteligir (sobre incomplexos) nem sobre os opostos contrários assentir e dissentir (sobre complexos). Os processos cognitivos são todos determinados, ou seja, para um único efeito possível, caindo sob a "natureza", porque, em havendo a apreensão dos conceitos que possibilita a união ou a separação dos mesmos no ato judicativo ou então a não-apreensão de algum deles, o intelecto é de si determinado ao assentimento/dissentimento ou de si obrigado a suspender o assentimento; em qualquer dos casos, o intelecto não tem em si poder tanto para o entender quanto para o não-entender, mas um desses atos segue-se imediatamente. Face ao conteúdo de um objeto proposicional $P$, em relação

lógico-epistemológica da proposição "A vontade quer b" segundo um quarto tipo (aristotélico) de proposição "por si", em IX, q. 15, n. 24-25 e 28-29. Por semelhante modo, em concomitância à irredutibilidade causal de certas proposições contingentes, o caráter lógico-semântico da sua caracterização como "per se notae" e "immediatae", portanto, da sua "perseidade" e "imediaticidade" (fala-se de "immediatio" em Ordinatio I, d. 8, p. 2, q. un., n. 300 (ed. Vat.: IV, 325)) como proposições (cf. as referências da nota 23) pode ganhar explanação pela pura e simples ausência de causa intermediária entre a causa imediata e o efeito imediato: há ao menos alguns estados de coisas (precipuamente volições, em analogia a relações causais imediatas na natureza: IX, q. 15, n. 25, 28-29) assim constatados como proposições contingentes descritivas, para cujo conhecimento não há nem precisa haver razão proposicional além da proposição constatada mesma, cuja verdade é conhecida, então, só pelos termos apreendidos - sentido básico do per se notum scotista - e constatados numa relação causal imediata e por si (IX, q. 15, n. 24). Cf. também G. Sondag, Duns Scot - La métaphysique de la singularité, p. 206-208.

49 Sobre isso, cf. R. H. Pich, Der Begriff der wissenschaftlichen Erkenntnis nach Johannes Duns Scotus, 5.2.1 e 5.2.2.

50 Cf. P. C. Vier, Evidence and its Function according to John Duns Scotus, p. 121s., 124-128. Cf. ainda Duns Scotus, Ordinatio IV, d. 49, q. 8, n. 5 (ed. Wadding: X, 498): “(...); sed cognitio intuitiua competit sensui: ergo multo magis intellectui: (...). Praeterea, si non haberemus de aliquo cognitionem intuitiuam, non sciremus de actibus nostris si insunt nobis, vel non certitudinaliter (de actibus dico intrinsecis) sed hoc est falsum: (...)". Também A. B. Wolter, Commentary, in: John Duns Scotus, op. cit., p. 66, incluindo nota 71 (referindo-se a Quodlibet q. 16 (ed. Vivès: XXVI, 180-201), Lectura I, d. 39, q. 1-5, n. 54 (ed. Vat.: XVII, 497) e Ordinatio I, d. 49, q. 10, n. 10 (ed. Vivès: XXI, 333)), insiste nesse "evidentissimum". Eu mencionaria, ainda, Duns Scotus Lectura I, d. 2, p. 1, q. 1, n. 56 (ed. Vat.: XVI, 131); Lectura I, d. 39, q. 1-5, n. 40 (ed. Vat.: XVII, 491); Reportatio examinata I, d. 39-40, q. 1-3, n. 26-30 (ed. Söder (2005): 76-80). 
ao qual pode-se conceber atos contrários - "Julgo que $P$ é verdadeiro" e "Julgo que $P$ é falso" ou ainda "Sei que $P$ é verdadeiro" e "Não sei se $P$ é verdadeiro" -, o intelecto, quando ou bem compreende aquele conteúdo ou o entretém mentalmente, não tem o poder tanto de assentir quanto de dissentir, tampouco de realizar o assentimento ou de suspender o assentimento ${ }^{52}$ (cf. também IX, q. 15, n. 36). ${ }^{53}$ Tanto mais isso confirma que a vontade como princípio causal é irredutível a qualquer outro princípio causal que não ela mesma, que o seu modo de agir lhe é estritamente próprio: ela é uma potência "livremente ativa", cujo modo de operação nem sequer é comparável ao modo de operação de fenômenos da "natureza" (cf. IX, q. 15, n. 43-45), seja se são, ali, "racionais" (como o intelecto o é "num sentido qualificado", enquanto préexigido ao ato da potência racional que, sendo a "vontade determinante" indeterminada ao próprio ato e por meio de cujo operar o intelecto é determinado quanto à causalidade que tem sobre os atos extrínsecos, Aristóteles chamaria, então, de "desejo" ou "prohairesis" (cf. IX, q. 15, n. 38-40))54 ou "irracionais" ("sem-razão") e para efeitos opostos, tal como em potências da natureza, a exemplo do calor do sol ou da frieza do ar. Entre a vontade e os fenômenos naturais lato sensu há uma oposição operativa..$^{55}$

XVI. De modo notório, pois, em IX, q. 15 em n. 35-41 Scotus tenta reconciliar a interpretação que fez com o pensamento de Aristóteles, cuja distinção era entre

51 Cf. A. B. Wolter, Commentary, in: John Duns Scotus, op. cit., p. 67.

52 Cf., por exemplo, Duns Scotus Lectura II, d. 25, q. un., n. 35-37 (ed. Vat.: VIII, 239-240). Scotus entende que a contingência "intelectual" com respeito aos atos de assentir e de dissentir pode apenas ter como resultado que o intelecto, por vezes, comete enganos. Se a liberdade estivesse fundada na contingência dos atos do intelecto, ela seria "algo miserável". Cf. Lectura II, d. 25, q. un., n. 35 (ed. Vat.: VIII, 239): "Item, ratio non potest demonstrative syllogizare nisi de oppositis, sed de altero sophistice et defective; igitur si propter talem indifferentiam in intellectu, quia potest iudicare de oppositis', esset libertas in voluntate, sequeretur quod libertas esset in voluntate, quia habet cognitionem defectibilem, et haec misera esset libertas!".

$53 \mathrm{O}$ que equivale a dizer que o intelecto, juntamente com o seu objeto, é causa suficiente do conhecimento da verdade e do assentimento que lhe presta o intelecto, sendo que a vontade não concorre em nada para a intelecção como tal; cf. R. Vier, A essência da liberdade na doutrina de João Duns Escoto, in: A. Garcia (org.), op. cit., p. 23-24. Embora o ponto tenha validade comum, é verdade que, em Metafísica IX, 2 e 5, Aristóteles não faz referência explícita a atos do intelecto puramente especulativo, mas a atos do intelecto prático; cf. C. González Ayesta, Cuestión 15 - Comentario, in: Juan Duns Escoto, Naturaleza y voluntad, Quaestiones super libros Metaphysicorum Aristotelis, IX, q. 15, p. 86-87.

54 Cf. também Duns Scotus, Quaestiones quodlibetales q. 16, n. [14] 41 (ed. Alluntis: 603-604). Não pode ser objeto de estudo, na presente exposição, o quanto Scotus efetivamente respeita a intenção do texto de Aristóteles em Metafísica IX 2 e 5, tampouco se identifica, em Aristóteles, as condições suficientes para um conceito de vontade; sobre isso, cf. também C. González Ayesta, Introducción, in: Juan Duns Escoto, op. cit., p. 19s.

55 Ibid., q. 16, n. [15] 42 (ed. Alluntis: 604): "Ad propositum, dico quod, licet aliquod principium posset concurrere in agendo cum voluntate, puta, secundum aliquos obiectum, secundum aliquos intellectus, et illud concurrens, quantum est ex se, sit naturaliter activum, tamen voluntas, per se loquendo, nunquam est principium activum naturaliter, quia esse naturaliter activum et esse libere activum, sunt primae differentiae principii activi, et voluntas, unde voluntas, est principium activum libere. Non magis igitur potest voluntas esse naturaliter activa quam natura, ut est principium distinctum contra voluntatem, potest esse libere activa". Cf. também R. Vier, A essência da liberdade na doutrina de João Duns Escoto, in: A. Garcia (org.), op. cit., p. 27. 
potências irracionais e racionais. Em resumo, se a qualificação "racional" de uma potência for entendida como "agindo com a razão", tendo de si e com respeito ao seu operar o poder para opostos contrários e, a partir disso, sobre os atos das potências inferiores que controla (IX, q. 15, n. 41), então a investigação cuidadosa leva à conclusão de que isso se aplica tão-somente à vontade. A título de construção teórica, essa abordagem convida a revisitar a repercussão que a teoria anselmiana das afecções exerceu sobre Scotus - explanada particularmente em Ordinatio II, d. 6, q. 1-2. Reza a visão de Scotus acerca das afecções que a vontade, comparada à affectio iustitiae, é de si (ou inatamente) um poder da alma unido à razão: é, antes de mais, a inclinação inata da alma à justiça, ou, mais exatamente, ao bem em si tal como apresentado pela razão - independentemente da inclinação natural do sujeito à "vantagem" (affectio commodi), ou ao próprio bem da realização natural, que pode ser objeto de um non velle, mesmo que não de um nolle. ${ }^{56} \mathrm{~A}$ vontade, a partir daí, tem, sim, desejo natural intrínseco para agir conforme à razão, muito embora seja livre não por causa disso, mas porque e quando, em se autodeterminando e causando com indeterminação, age em conformidade com a reta razão. Levando-se, pois, às últimas conseqüências a distinção que Aristóteles faz entre potências racionais e irracionais, e respeitando a sua classificação do intelecto como potência racional, ter-se-á de dizer que a diferença não convém ao intelecto quanto ao seu ato próprio ou a um ato seu concorrente com o de uma potência inferior, "tomando-se precisamente o seu ato": ora, se nos dois casos ele "cai sob a natureza", melhor é para o intelecto a distinção entre potências segundo o "natural" e o "livre" (IX, q. 15 , n. 40 ), na qual ele bem se situa entre as causas naturais. ${ }^{57}$

XVII. Todas as potências ativas que não são e nem estão, ao operar, sob o poder da vontade - como o intelecto e outras potências de si mesmas irracionais - podem apenas ser igualadas a causas naturais. As potências racionais são igualadas à vontade a partir do estudo das suas operações que caem sob o princípio causal "livre" ou "contingente", de novo considerando primariamente os seus próprios atos (as volições) e derivadamente atos de potências que ela controla - tal como nas produções artísticas (IX, q. 15, n. 41). Recuperando, assim, a divisão de Aristóteles, Scotus responde com detalhes, em IX, q. 15, n. 42-62, a diversas objeções à sua interpretação da divisão aristotélica ${ }^{58}$ - incluindo nessas respostas e também naquelas aos argumentos iniciais (IX, q. 15, n. 63-73) elementos importantes sobre 0 indeterminismo visto no "poder para opostos", ali onde esse se submete a uma desejada linguagem de cláusulas temporais ${ }^{59}$ como "naquele e para aquele instante"

56 Estudos fundamentais sobre a "affectio commodi" e a "affectio iustitiae" na teoria da ação e moral de Scotus continuam sendo A. B. Wolter, Native Freedom of the Will as a Key to the Ethics of Scotus, in: M. Mc. Adams (ed.), The Philosophical Theology of John Duns Scotus, p. 148-162, e J. Boler, Transcending the Natural: Duns Scotus on the Two Affections of the Will, in: American Catholic Philosophical Quarterly, p. 109-126. Cf. ainda J. Bolen, An Image for the Unity of Will in Duns Scotus, in: Journal of the History of Philosophy, p. 23-44; L. Honnefelder, Duns Scotus, p. 115-117; G. Sondag, op. cit., p. 208-211.

57 Cf. A. B. Wolter, Commentary, in: John Duns Scotus, op. cit., p. 67.

58 Cf. A. B. Wolter, Commentary, in: John Duns Scotus, op. cit., p. 68.

59 Às quais procurei chamar a atenção na tradução abaixo, cf. as notas 155, 156, 161, 171, 174, 176 e 180. 
da volição (IX, q. 15, n. 59-61, 63-65). Desse modo, abre-se margem para somar à autodeterminação a outra condição necessária - a do indeterminismo - para descrever a estrita contingência e liberdade metafísica do ato da vontade. ${ }^{60} \mathrm{~A}$ simultaneidade de opostos contrários no ato da vontade ou a relação estrutural não temporal - de anterioridade (a potência relacionada com o ato e/ou efeito oposto) e posterioridade (o ato da vontade efetivado acidentalmente) como estrutura ontológica interna de um mesmo instante de tempo indivisível ou do "agora" presente de uma volição fatual ${ }^{61}$ é descrição mesma do que é a contingência ou o modo de ser - a realidade - do ato a partir do princípio operativo. De qualquer modo, a proposta de definir a contingência - em termos de "contingência sincrônica" de opostos contrários, como estabeleceu a pesquisa moderna ${ }^{62}$ - não é alvo maior da Questão 15 , mas é objetivo central dos tratados sobre a contingência. ${ }^{63}$

XVIII. Por outro lado, a autodeterminação como condição necessária de uma potência genuinamente racional, porque livre ou capaz de causar opostos contrários, ganha destaque na Questão 15 como elemento ao menos logicamente co-extensivo a um poder para opostos ou princípio causal indeterminado de si: uma potência como princípio operativo é genuinamente para opostos ou é um princípio causal indeterminado, portanto, racional, sse pode determinar a si na sua ação própria, portanto, determina a si na sua ação (ou volição). Numa sentença simples e definitiva, Scotus diz mesmo que a vontade se determina de modo livre tal como uma "que pode determinar a si": "E por isso mesmo ela é potência, porque ela pode algo, pois pode determinar a si" (IX q. 15 n. 41). ${ }^{64}$ As referências à conexão estrita entre autodeterminação e genuíno poder para opostos (genuína causalidade indeterminada) são abundantes na Questão 15: n. 41, 43, 45-48, 52, 63, etc. Se é

60 Cf. sobre isso R. H. Pich, Contingência e liberdade, in: João Duns Scotus, Poder, conhecimento e contingência, Coleção Pensamento Franciscano vol. 11, 2008 [no prelo].

61 Cf. A. Vos, The Philosophy of John Duns Scotus, p. 223-263.

62 Cf., por exemplo, S. Knuuttila, Time and Modality in Scholasticism, in: S. Knuuttila (ed.), Reforging the Great Chain of Being. Studies of the History of Modal Theories, p. 163-257; idem, Duns Scotus' Criticism of the "Statistical" Interpretation of Modality, in: W. Kluxen (Hrsg.), Miscellanea Mediaevalia 13/1 - Sprache und Erkenntnis im Mittelalter, p. 44-450; A. Vos Jaczn et alii, John Duns Scotus Contingency and Freedom - Lectura I39, 1994; J. R. Söder, Kontingenz und Wissen. Die Lehre von den futura contingentia bei Johannes Duns Scotus, 1999. Cf. ainda C. G. Normore, Duns Scotus's Modal Theory, in: Th. Williams (ed.), The Cambridge Companion to Duns Scotus, p. 130-137. R. Cross, Duns Scotus on God, p. 57-58.

63 Cf., em especial, Lectura I, d. 39, q. 1-5, n. 1-93 (ed. Vat.: XVII, 481-510); Ordinatio I, d. 38, q. 2,-d. 39, q. 1-5, n. [1]-[37] (ed. Vat.: VI, 401-444); Reportatio examinata I, d. 38, q. 1-2 e d. 39-40, q. 1-3, n. 1-83 (ed. Söder (2005): 66-117).

64 Noutros contextos, Scotus pusera muito claramente que "autodeterminação" equivale a uma forma de "automovimento"; cf. Duns Scotus Duns Scotus, Quaestiones quodlibetales q. 16, n. [6] 22 (ed. Alluntis: 591), e naturalmente Quaest. sup. libr. Metaph. Arist., IX, q. 14, n. 1-126, p. 625-673. Aqui, como é sabido, Scotus rejeitou o valor metafísico ou a validade universal do princípio aristotélico "quidquid movetur ab alio movetur". Cf. o estudo referencial de R. R. Effler, John Duns Scotus and the Principle "omne quod movetur ab alio movetur", 1962. Cf. também R. Vier, A essência da liberdade na doutrina de João Duns Escoto, in: A. Garcia (org.), op. cit., p. 24-25; P. King, Scotus on Metaphysics, in: Th. Williams (ed.), The Cambridge Companion to Duns Scotus, p. 46-48. 
verdade que a vontade é um poder racional também porque opera com a razão, tal que a sua operação nunca se dá sem a razão, havendo mesmo certa dependência da vontade para com o intelecto no sentido do conhecimento prévio do seu querer como concausa que opera por si (IX q. 15 n. 53), não sendo a vontade na estrutura da ação o princípio absolutamente primeiro, ${ }^{65}$ a vontade ainda assim é, na volição, causa principal: se a razão explica as ações humanas, ainda assim não as determina, porque a vontade escolhe entre alternativas consideradas pela razão determinando-se a uma delas, e não sofrendo nem determinação passiva nem necessitação operativa. O máximo que o "voluntarismo" de Scotus significa, assim, é que a autodeterminação para realizar a ação procede exclusivamente da vontade. ${ }^{66}$

XIX. Para os atos da vontade como genuína potência racional é correto admitir, pois, os seus modos da indeterminação e também a concepção da mesma como causa autodeterminante e não mais redutível da volição. ${ }^{67}$ Como pôs em síntese L. Honnefelder, o poder para opostos da vontade, simultâneo no modus eliciendi, está (i) na "liberdade de especificação do querer" (libertas specificationis), isto é, de querer a (velle) ou de não-querer/"desquerer" a (nolle), (ii') na "liberdade de exercício do querer" (libertas exercitii), ou seja, de querer (velle) a ou $b$ ( $a$ ou $\neg a$ ), respectivamente, de querer (velle) um querer a ou um desquerer $a$, e (ii") na liberdade (de exercício) de recusar exercer um ato do querer (non velle, isto é, "não [exercer um] querer"). ${ }^{68}$ Autodeterminarse, em Quaestiones super libros metaphysicorum Aristotelis IX q. 15, parece pressupor e, portanto, incluir causal e irredutivelmente, da parte da vontade, uma indeterminatio ex se (metafisicamente antes), com respeito a (i), (ii') e (ii"). Essa indeterminação, porém, é de "ilimitação de atualidade" (ex illimitatione actualitatis), na medida em que a vontade pode passar, por si mesma, para uma determinatio específica. ${ }^{69}$

65 Cf. Duns Scotus, Quaestiones quodlibetales q. 16, n. [15] 43 (ed. Alluntis: 605): “(...): Omne agens naturale, vel est omnino primum vel, si est posterius, erit ab aliquo priori naturaliter determinatum ad agendum; voluntas autem nunquam potest esse agens omnino primum, sed nec potest esse determinata naturaliter ab aliquo agente superiori; quia ipsamet est tale activum quod seipsam determinat in agendo, (...)".

66 Como apontou R. Cross, Duns Scotus, p. 89, a ética de Scotus não é uma teoria de comandos (voluntaristas) divinos; se há dois tipos de éticas de comandos divinos, isto é, (a) o comando de Deus é tanto necessário quanto suficiente para uma ação moral correta e (b) o comando de Deus é necessário, mas não é suficiente para ação moral correta, Scotus se situa no máximo em harmonia com a segunda. Além disso, como foi mostrado no brilhante ensaio de H. Möhle, Freiheit und Verantwortung. Zum Verhältnis kompatibilistischer und inkompatibilistischer Willenstheorien, in: Jahrbuch für Wissenschaft und Ethik, p. 44-48, a teoria scotista da vontade tem recursos para estabelecer que o ato da vontade (a) possui um sujeito ou um agente e (b) possui, ademais, um agente que opera racionalmente, daí, causalmente a partir de razões. Cf. também Duns Scotus, Lectura I, d. 8, p. 2, q. un., n. 279 (ed. Vat.: XVII, 105); Ordinatio I, d. 8, p. 2, q. un., n. 299 (ed. Vat.: IV, 325); L. Honnefelder, Die Kritik des Johannes Duns Scotus am kosmologischen Nezessitarismus der Araber: Ansätze zu einem neuen Freiheitsbegriff, in: J. Fried (Hrsg.), Die Abendländische Freiheit vom 10. zum 14 Jahrhundert, p. 261-262; M. B. Ingham, La genèse de la volonté rationnelle: de la Lectura à la Reportatio II, 25, in: O. Boulnois; E. Karger; J.-L. Solère; G. Sondag (eds.), Duns Scot à Paris 1302-2002, p. 417-422.

68 Isto é, um querer a ou $b(a$ ou $\neg a)$, respectivamente, um querer a ou um desquerer $a$.

69 Cf. sobre este parágrafo L. Honnefelder, Duns Scotus, p. 113-120. Cf. Duns Scotus, Lectura I, d. 39, q. 1-5, n. 39-40 (ed. Vat.: XVII, 490-491). Cf. ainda C. G. Normore, Duns Scotus's Modal Theory, in: Th. Williams (ed.), op. cit., p. 143-144. 


\section{Estrutura ${ }^{70}$}

\section{Questões sobre os livros da metafísica de Aristóteles, Livro IX, q. 15 - Se a diferença assinalada por Aristóteles entre as potências racionais e irracionais é conveniente}

ARGUMENTOS CONTRA E A FAVOR: n. 1-8

Argumentos contrários: n. 1-7

Primeiro argumento contrário: $\mathrm{n} .1$

Objeção e resposta à objeção: n. 2

Segundo argumento contrário: n. 3

Terceiro argumento contrário: n. 4

Quarto argumento contrário: n. 5

Quinto argumento contrário: n. 6

Sexto argumento contrário: $n .7$

Argumento que ratifica a questão: n. 8

I - RESPOSTA À QUESTÃO: n. 9-62

A - Artigo 1: Sobre a diferença assinalada por Aristóteles entre as potências racionais e irracionais: n. 9-19

1 - De que modo a diferença deve ser entendida: n. 10-12

2 - Qual é a causa da diferença entre as potências: n. 13-19

B - Artigo 2: Sobre a diferença em si: n. 20-41

1 - Sobre a diferença entre natureza e vontade: n. 20-34

A primeira distinção da potência ativa é segundo o modo diverso de produzir uma operação: n. 21-23

Sobre a causa desta diferença, a saber, que a natureza é tão-somente de um único efeito e a vontade é de efeitos opostos: o modo como o efeito imediato é relacionado com a causa imediata: n. 24-30

Sobre a indeterminação de insuficiência e de suficiência: n. 31-34

2 - Sobre a intenção de Aristóteles: n. 35-41

Se a vontade pode ser considerada dentro da distinção aristotélica entre potência irracional e racional: n. 35

70 Levei em consideração que A. B. Wolter, Preface, in: John Duns Scotus, A Treatise on Potency and Act Questions on the Metaphysics of Aristotle Book IX, Introduction and Commentary, Latin Text and English Translation by A. B. Wolter, St. Bonaventure (N.Y.), The Franciscan Institute, 2000, p. 9, na sua edição, modificou levemente os cabeçalhos das questões. Não obstante isso, o texto traduzido segue fielmente a edição crítica contemporânea, a saber, Ioannes Duns Scotus, Opera Philosophica IV - Quaestiones super libros metaphysicorum Aristotelis Libri VI-IX, in: R. Andrews; G. Etzkorn; G. Gál; R. Green; F. Kelley; G. Marcil; T. Noone; R. Wood (eds.), St. Bonaventure, Franciscan Institute Publications, 1997, IX, q. 15, n. $1-73$, p. $675-699$. 
O intelecto e a vontade são comparados com os atos próprios que produzem: n. 36 O intelecto e a vontade são comparados com os atos de potências inferiores: n. 37 De que modo o intelecto é uma potência irracional e de que modo uma racional: n. 38 A vontade como determinante da causalidade exterior do intelecto: $\mathrm{n}$. 39 $O$ intelecto e a diferença em questão, segundo a intenção de Aristóteles: n. 40 A vontade como propriamente racional: $n .41$

C - Resposta às objeções contra a via de Aristóteles: n. 42-62

Quanto ao primeiro argumento contrário à via de Aristóteles (n. 15): n. 43-45

Quanto ao segundo argumento contrário à via de Aristóteles (n. 16-18): n. 46-53 Quanto ao terceiro argumento contrário à via de Aristóteles (n. 19): n. 54-62

II - RESPOSTA AOS ARGUMENTOS PRINCIPAIS: n. 63-73

Resposta ao primeiro argumento contrário (n. 1): n. 63-65

Resposta ao segundo argumento contrário (n. 3): n. 66-67

Resposta ao terceiro argumento contrário (n. 4): n. 68

Resposta ao quarto argumento contrário (n. 5): n. 69

Resposta ao quinto (melhor: sexto) argumento contrário (n. 7): n. 70-72

Resposta ao sexto (melhor: quinto) argumento contrário (n. 6): n. 73

\section{Referências bibliográficas}

\section{(Fontes)}

ARISTOTELES. Metaphysik - Erster Halbband (Bücher I-VI). In: SEIDL, Horst (Hrsg.). Aristoteles' Metaphysik. Griechisch-Deutsch. Dritte, verbesserte Auflage. Hamburg: Felix Meiner Verlag, 1989, p. 1-263.

. Metaphysik - Zweiter Halbband (Bücher VII-XIV). In: SEIDL, Horst (Hrsg.). Aristoteles' Metaphysik. Griechisch-Deutsch. Dritte, verbesserte Auflage. Hamburg: Felix Meiner Verlag, 1991, p. 1-371.

DUNS ESCOTO, Juan. Cuestiones cuodlibetales. Edición bilingüe. Introducción, resúmenes y versión de Felix Alluntis. Madrid: Biblioteca de Autores Cristianos, 1968.

DUNS ESCOTO, Juan. Naturaleza y voluntad, Quaestiones super libros metaphysicorum Aristotelis, IX, q. 15. Introducción, traducción y notas de Cruz González Ayesta. Pamplona, Cuadernos de Anuario Filosófico - Série Universitária 199, 2007.

DUNS SCOTUS, Ioannes. Opera omnia I. Ordinatio: prologus. Civitas Vaticana: Typis Polyglottis Vaticanis, 1950.

. Opera omnia III. Ordinatio - Liber primus: distinctio tertia. Civitas Vaticana: Typis Polyglottis Vaticanis, 1954.

. Opera omnia IV. Ordinatio - Liber primus: a distinctione quarta ad decimam. Civitas Vaticana: Typis Polyglottis Vaticanis, 1956.

Opera omnia VI. Ordinatio - Liber primus: a distinctione vigesima sexta ad quadragesimam octavam. Civitas Vaticana: Typis Polyglottis Vaticanis, 1963.

. Opera omnia XVI. Lectura in librum primum sententiarum: prologus et distinctiones a prima ad septimam. Civitas Vaticana: Typis Polyglottis Vaticanis, 1960. 
DUNS SCOTUS, Ioannes. Opera omnia XVII. Lectura in librum primum sententiarum: a distinctione octava ad quadragesimam quintam. Civitas Vaticana: Typis Polyglottis Vaticanis, 1966.

DUNS SCOTUS, Ioannes. Opera Philosophica III - Quaestiones super libros metaphysicorum Aristotelis Libri I-V. In: ANDREWS, R.; ETZKORN, G.; GÁL. G.; GREEN, R.; KELLEY, F.; MARCIL, G.; NOONE, T.; WOOD, R. (eds.). B. Ioannis Duns Scoti Opera Philosophica IV Quaestiones super libros metaphysicorum Aristotelis Libri VI-IX. St. Bonaventure: Franciscan Institute Publications, 1997.

Opera Philosophica IV - Quaestiones super libros metaphysicorum Aristotelis Libri VI-IX. In: ANDREWS, R.; ETZKORN, G.; GÁL. G.; GREEN, R.; KELLEY, F.; MARCIL, G.; NOONE, T.; WOOD, R. (eds.). B. Ioannis Duns Scoti Opera Philosophica IV - Quaestiones super libros metaphysicorum Aristotelis Libri VI-IX. St. Bonaventure: Franciscan Institute Publications, 1997.

DUNS SCOTUS, Ioannes. Reportatio parisiensis examinata I d. 39-40. In: Idem. Pariser Vorlesungen über Wissen und Kontingenz - Reportatio parisiensis examinata I 38-44. Lateinisch-Deutsch. Herausgegeben, übersetzt und eingeleitet von Joachim R. Söder. Freiburg: Verlag Herder, 2005, p. 66-117.

DUNS SCOTUS, Johannes. Opera omnia X: Ordinatio IV, d. 43 - Ordinatio IV, d. 50. (Reprografischer Nachdruck der L. Wadding-Ausgabe Lyon 1639). Hildesheim: Georg Olms Verlagsbuchhandlung, 1968.

DUNS SCOTUS, John. A Treatise on Potency and Act - Questions on the Metaphysics of Aristotle Book IX. Introduction and Commentary, Latin Text and English Translation by Allan B. Wolter. St. Bonaventure (New York): The Franciscan Institute, 2000.

\section{(Literatura secundária)}

ANDREWS, R. et alii. Introduction. In: ANDREWS, R. et alii (eds.). Ioannis Duns Scoti Opera Philosophica III - Quaestiones super libros metaphysicorum Aristotelis Libri I-V. St. Bonaventure: Franciscan Institute Publications, 1997, p. vii-l.

BOLER, John. An Image for the Unity of Will in Duns Scotus. In: Journal of the History of Philosophy, 32: 1(1994), p. 23-44.

. The Ontological Commitment of Scotus's Account of Potency in his Questions on the metaphysics, Book IX. In: HONNEFELDER, Ludger; DREYER, Mechtild; WOOD, Rega (eds.). John Duns Scotus - Metaphysics and Ethics. Leiden: E. J. Brill, 1996, p. 145-160.

. Transcending the Natural: Duns Scotus on the Two Affections of the Will. In: American Catholic Philosophical Quarterly, 67 (1993), p. 109-126.

CROSS, Richard. Duns Scotus. New York/Oxford: Oxford University Press, 1999.

. Duns Scotus on God. Aldershot: Ashgate, 2005.

DE BONI, Luis Alberto. Sobre a vida e a obra de Duns Scotus. In: Patristica et Mediaevalia, 27:1 (2006), p. 51-72.

EFFLER, Roy R. John Duns Scotus and the Principle "omne quod movetur ab alio movetur". St. Bonaventure/Louvain/Paderborn: The Franciscan Institute/E. Nauwelaerts/F. Schöningh, 1962.

GONZÁLEZ AYESTA, Cruz. Comentario. Cuestión 15 - Comentario. In: DUNS ESCOTO, Juan. Naturaleza y voluntad, Quaestiones super libros metaphysicorum Aristotelis, IX, q. 15. Introducción, traducción y notas de Cruz González Ayesta. Pamplona, Cuadernos de Anuario Filosófico - Série Universitária 199, 2007, p. 75-103.

. Introducción. In: DUNS ESCOTO, Juan. Naturaleza y voluntad, Quaestiones super libros metaphysicorum Aristotelis, IX, q. 15. Introducción, traducción y notas de Cruz 
González Ayesta. Pamplona, Cuadernos de Anuario Filosófico - Série Universitária 199, 2007, p. 5-32.

HÖFFE, Otfried. Aristoteles. 3., überarbeitete Auflage. München: Beck Verlag, 2006.

HONNEFELDER, Ludger. Die Kritik des Johannes Duns Scotus am kosmologischen Nezessitarismus der Araber: Ansätze zu einem neuen Freiheitsbegriff. In: FRIED, Johannes (Hrsg.). Die Abendländische Freiheit vom 10. zum 14 Jahrhundert. Der Wirkungszusammenhang von Idee und Wirklichkeit im europäischen Vergleich. Sigmaringen: Jan Thorbecke Verlag, 1991, p. 249-263.

. Duns Scotus. München: Verlag C. H. Beck, 2005.

INGHAM, Mary Elizabeth. La genèse de la volonté rationnelle: de la Lectura à la Reportatio II, 25. In: BOULNOIS, Olivier; KARGER, Elizabeth; SOLÉRE, Jean-Luc; SONDAG, Gérard (eds.). Duns Scot à Paris 1302-2002. Turnhout: Brepols, 2004, p. 409-423.

KING, Peter. Scotus on Metaphysics. In: WILLIAMS, Thomas (ed.). The Cambridge Companion to Duns Scotus. Cambridge: Cambridge University Press, 2003, p. 15-68.

KNUUTTILA, Simo. Duns Scotus' Criticism of the "Statistical" Interpretation of Modality. In: KLUXEN, Wolfgang (Hrsg.). Miscellanea Mediaevalia Band 13/1 - Sprache und Erkenntnis im Mittelalter. Berlin: Walter de Gruyter, 1981, p. 441-450.

. Time and Modality in Scholasticism. In: KNUUTTILA, Simo (ed.). Reforging the Great Chain of Being. Studies of the History of Modal Theories. Dordrecht: D. Reidel Publishing Company, 1981, p. 163-257.

LISKE, Michael-Thomas. Inwieweit sind Vermögen intrinsische dispositionelle Eigenschaften? (E 1-5). In: RAPP, Christof (Hrsg.). Aristoteles Metaphysik: Die Substanzbücher (Z, H, $\Theta$ ). Klassiker Auslegen Band 4. Berlin: Akademie Verlag, 1996, p. 253-287.

MARRONE, Steven P. Revisiting Duns Scotus and Henry of Ghent on Modality. In: HONNEFELDER, Ludger; DREYER, Mechtild; WOOD, Rega (eds.). John Duns Scotus Metaphysics and Ethics. Leiden: E. J. Brill, 1996, p. 175-189.

MÖHLE, Hannes. Freiheit und Verantwortung. Zum Verhältnis kompatibilistischer und inkompatibilistischer Willenstheorien. In: Jahrbuch für Wissenschaft und Ethik, 10 (2005), p. 35-53.

MORRISON, Donald. Substance as Cause: Metaphysics Z 17. In: RAPP, Christof (Hrsg.). Aristoteles Metaphysik: Die Substanzbücher $(Z, H, \Theta)$. Klassiker Auslegen Band 4. Berlin: Akademie Verlag, 1996, p. 193-207.

NORMORE, Calvin G. Duns Scotus's Modal Theory. In: WILLIAMS, Thomas (ed.). The Cambridge Companion to Duns Scotus. Cambridge: Cambridge University Press, 2003, p. 129-160.

PICH, Roberto Hofmeister. Contingência e liberdade. In: João Duns Scotus. Poder, conhecimento e contingência. Prefácio, introdução, tradução e notas de Roberto Hofmeister Pich. Coleção Pensamento Franciscano vol. 11. Porto Alegre/Bragança Paulista: Edipucrs/ Editora Universitária São Francisco, 2008 [no prelo].

. Der Begriff der wissenschaftlichen Erkenntnis nach Johannes Duns Scotus. Bonn, Universität Bonn, 2001 (Tese de Doutorado).

. Vontade livre e contingência: sobre a análise scotista do ato volitivo. In: COSTA, Marcos R. N.; DE BONI, Luis Alberto (Orgs.). A ética medieval face aos desafios da contemporaneidade. Porto Alegre: Edipucrs, 2004, p. 407-451.

RAPP, Christof. Aristoteles Metaphysik: Die Substanzbücher (Z, H, $\Theta$ ). Klassiker Auslegen Band 4. Berlin: Akademie Verlag, 1996.

. Einleitung: Die Substanzbücher der Metaphysik. In: RAPP, Christof (Hrsg.). Aristoteles Metaphysik: Die Substanzbücher $(Z, H, \Theta)$. Klassiker Auslegen Band 4. Berlin: Akademie Verlag, 1996, p. 1-26. 
. Substanz als vorrangig Seiendes (Z 1). In: RAPP, Christof (Hrsg.). Aristoteles Metaphysik: Die Substanzbücher $(Z, H, \Theta)$. Klassiker Auslegen Band 4. Berlin: Akademie Verlag, 1996, p. 27-40.

ROSS, Sir David. Aristóteles. Lisboa: Publicações Dom Quixote, 1987.

SANTOGROSSI, Ansgar. Duns Scotus on Potency Opposed to Act in Questions on the Metaphysics, IX. In: The American Catholic Philosophycal Quarterly, 66:3 (1993), p. 55-76.

SEIDL, Horst. Einleitung. In: SEIDL, Horst (Hrsg.). Aristoteles' Metaphysik - Erster Halbband (Bücher I(A) - VI (E)). Griechisch-Deutsch. Dritte, verbesserte Auflage. Hamburg: Felix Meiner Verlag, 1989, p. xi-lxix.

. Kommentar. In: SEIDL, Horst (Hrsg.). Aristoteles' Metaphysik - Zweiter Halbband: Bücher VII(Z)-XIV(N). Griechisch-Deutsch. Dritte, verbesserte Auflage. Hamburg: Felix Meiner Verlag, 1991, S. 373-603.

SÖDER, Joachim Roland. Kontingenz und Wissen. Die Lehre von den futura contingentia bei Johannes Duns Scotus. Münster: Aschendorff, 1999.

SONDAG, Gérard. Duns Scot - La métaphysique de la singularité. Paris: Vrin, 2005.

VIER, Peter C. Evidence and its Function according to John Duns Scotus. St. Bonaventure (New York): The Franciscan Institute, 1951.

VIER, Raimundo. A essência da liberdade na doutrina de João Duns Escoto. In: GARCIA, Antônio (org.). Estudos de filosofia medieval - A obra de Raimundo Vier. Petrópolis/São Paulo/ Curitiba: Editora Vozes/Universidade São Francisco/Editora UFPR, 1997, p. 19-32.

VOS, Antonie. The Philosophy of John Duns Scotus. Edinburgh: Edinburgh University Press, 2006.

VOS JACZN, A. et alii. John Duns Scotus Contingency and Freedom - Lectura I 39. Introduction, translation and commentary. Dordrecht/Boston/London: Kluwer Academic Publishers, 1994.

WEIDEMANN, Hermann. antiphasis/Widerspruch. In: HÖFFE, Otfried (Hrsg.). AristotelesLexikon. Stuttgart: Alfred Kröner Verlag, 2005, p. 50-52.

. dynamis/Vermögen, Möglichkeit. In: HÖFFE, Otfried (Hrsg.). (Hrsg.). AristotelesLexikon. Stuttgart: Alfred Kröner Verlag, 2005, p. 139-144.

. enantion / konträr entgegengesetzt. In: HÖFFE, Otfried (Hrsg.). Aristoteles-Lexikon. Stuttgart: Alfred Kröner Verlag, 2005, p. 174-176.

Zum Begriff des ti ên einai und zum Verständnis von Met. Z 4, 1029b22-1030a6). In:

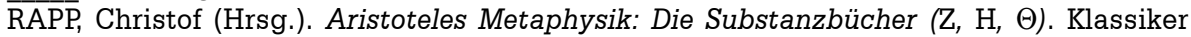
Auslegen Band 4. Berlin: Akademie Verlag, 1996, p. 75-103.

WILLIAMS, Thomas. Introduction - The Life and Works of John Duns the Scot. In: WILLIAMS, Thomas (ed.). The Cambridge Companion to Duns Scotus. Cambridge: Cambridge University Press, 2003, p. 1-14.

. The Works of John Duns Scotus. In: http://www.nd.edu/ wwillia5/dunsscotus/ works/html, consultado em 14.05.2008.

WILSON, Gordon. The Presence of Henry of Ghent in Scotus's Quaestiones super libros metaphysicorum. In: HONNEFELDER, Ludger; DREYER, Mechtild; WOOD, Rega (eds.). John Duns Scotus - Metaphysics and Ethics. Leiden: E. J. Brill, 1996, p. 107-124.

WOLTER, Allan B. Commentary. In: John Duns Scotus, A Treatise on Potency and Act Questions on the Metaphysics of Aristotle Book IX. Introduction and Commentary, Latin Text and English Translation by Allan B. Wolter. St. Bonaventure (New York): The Franciscan Institute, 2000, p. 21-68.

. Duns Scotus on the Will as Rational Potency. In: ADAMS, Marilyn McCord (ed.). The Philosophical Theology of John Duns Scotus. Ithaca: Cornell University Press, 1990, p. 163-180. 
. Introduction. In: John Duns Scotus, A Treatise on Potency and Act - Questions on the metaphysics of Aristotle Book IX. Introduction and Commentary, Latin Text and English Translation by Allan B. Wolter. St. Bonaventure (New York): The Franciscan Institute, 2000, p. 11-19.

. Preface. In: John Duns Scotus, A Treatise on Potency and Act - Questions on the Metaphysics of Aristotle Book IX. Introduction and Commentary, Latin Text and English Translation by Allan B. Wolter. St. Bonaventure (New York): The Franciscan Institute, 2000, p. 9.

\section{Tradução ${ }^{71}$}

\section{[675] Se a diferença assinalada por Aristóteles entre as potências racionais e irracionais é conveniente}

$\mathrm{Se}^{72}$ a diferença que Aristóteles assinala entre as potências ${ }^{73}$ racionais e irracionais é conveniente, ${ }^{74}$ a saber, que essas ${ }^{75}$ são de [efeitos] opostos, as outras ${ }^{76}$ de um único efeito.

1. Argumenta-se que não.

Primeiramente, sobre as [potências] racionais, assim: o que tem a potência é capaz daquilo que está naquela potência; logo, algum [agente] seria capaz de opostos [ao mesmo tempo].

2. Diz-se, assim como Aristóteles parece responder no texto, ${ }^{77}$ que [uma potência racional] não tem poder de fazer [efeitos] opostos ao mesmo tempo, embora tenha poder ao mesmo tempo para opostos.

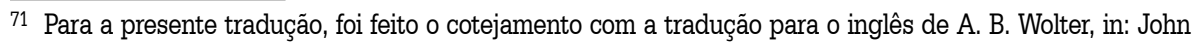
Duns Scotus, A Treatise on Potency and Act - Questions on the Metaphysics of Aristotle Book IX, p. 360407, e com a tradução para o espanhol de Cruz González Ayesta, in: Juan Duns Escoto, Naturaleza y voluntad, Quaestiones super libros Metaphysicorum Aristotelis, IX, q. 15, p. 33-73.

72 Esta questão está ausente no códice A até o meio do n. 71 ('os termos [de início e de fim] do movimento local').

73 Na forma plural ("potentiae") ou singular ("potentia"), nos casos possíveis, "potentia" é traduzida abaixo por "potência" e, em alguns casos, por "poder". Por semelhante modo, o verbo "posse" é o que está na base das formas verbais traduzidas como "poder", "ser capaz de" e ainda "ter o poder de". N. do T.

74 Aristot., Metaph. IX t. 3 (AL XXV2 170; $\Theta$ c. 2, 1046b2-6): “... [é preciso] claramente que algumas das potências sejam irracionais, outras com a razão... Mas, as que são com a razão, todas essas são de [efeitos] contrários, e as que [são] irracionais [são] cada uma de um único [efeito]".

75 A saber, as potências racionais. N. do T.

76 A saber, as potências irracionais. N. do T.

77 Aristot., Metaph. IX t. 10 (AL XXV3 184-185; $\Theta$ c. 5, 1048a5-10; 21-24): "É necessário, com efeito, que tais potências [irracionais], tão logo, tal como podem, se aproximem do passivo e do ativo, façam com efeito este e sofram, entretanto, aquele; que aquelas [potências racionais o façam] não é, entretanto, necessário. Pois, com efeito, todas estas [potências irracionais] [são] capazes de fazer uma única [atividade], aquelas [potências racionais], porém, [são capazes de atividades] contrárias, porque ao mesmo tempo farão contrários, [mas] isto, porém, [é] impossível. Logo, [é] necessário que haja alguma outra coisa que [seja] dominante. Chamo isto, porém, de desejo ou de prohairesis... E por causa disso, nem se ao mesmo tempo querem ou desejam fazer duas coisas ou contrários, não farão; pois não [é] desse modo que ao mesmo tempo têm potência para tanto, e nem há uma potência de fazer simultaneamente, visto que daquilo do que há [potência] assim ele fará". 
Contra: nesse 'agora' no qual se encontra um oposto, pergunto se poderá, no mesmo agora, dar-se um outro, ou não. Se sim, tem-se o propósito [em questão], como parece, que [se tem efeitos] opostos ao mesmo tempo. Se não, logo essa potência neste agora não é senão de um único efeito.

[676] 3. Ademais, em segundo lugar, [argumenta-se] assim: não há potência que não seja capaz de algo. Porém, aquela [potência] que é de [efeitos] opostos, visto que não tem poder ao mesmo tempo para [efeitos] opostos, não parece ter poder para algo a não ser que seja determinada [por alguma outra coisa], assim como é argumentado no texto, no capítulo $4 .{ }^{78}$ Uma [potência] determinada, porém, não parece ser senão de um único [efeito]; logo, enquanto potência parece ser tão-somente de um único [efeito].

4. Ademais, em terceiro lugar, [argumenta-se] assim: então seguir-se-ia que a vontade teria poder para um [efeito] oposto do [seu] fim e teria poder para o mal sob a razão de mal, bem como também para [efeitos] opostos dessas coisas. 0 conseqüente [é] falso, porque no capítulo 4 do Livro XII diz Aristóteles: "do [homem] livre não se permite que ocorra agir [casualmente]", ${ }^{79}$ etc.

5. Contra o outro membro, a saber, das [potências] irracionais, [argumenta-se] primeiramente assim:

O sol tem poder para efeitos opostos nesses [entes] inferiores; ele dissolve, pois, o gelo e resseca o barro; contudo, a potência dele é irracional.

6. Ademais, abaixo, no capítulo 7,80 o Filósofo alega que "toda potência é de contradição"; e declara que [isso] também [é válido] nas [potências] ativas.

7. Ademais, a [potência] racional, segundo Aristóteles, ${ }^{81}$ não é tida como sendo de [ambos os efeitos] opostos por si; mas, de um único [efeito] por si enquanto [0 efeito] de um hábito, [e] do outro [efeito] por acidente enquanto [efeito] de uma privação. Mas, a potência irracional é capaz de opostos dessa maneira; o frio, pois, é uma causa acidental do calor, e o que joga a bola contra a parede é a causa do [seu] rebatimento. Portanto, a diferença mencionada não é conveniente.

8. Pelo contrário é o Filósofo, no [seu] texto. ${ }^{82}$

78 Ibidem.

79 Aristot., Metaph. XII, t. 52 (AL XXV³ 266-267; $\Lambda$ c. 10, 1075a20): "Pois, todas as coisas, com efeito, são coordenadas ao uno, mas do mesmo modo como na casa aos livres não é permitido que façam o que quer que seja".

80 Aristot., Metaph. IX, t. 17 (AL XXV2 179; $\Theta$ c. 8, 1050b8).

81 Aristot., Metaph. IX, t. 3 (AL XXV2 170; $\Theta$ c. 2, 1046b7-15).

82 Aristot., Metaph. IX, t. 3 (AL XXV2 169; $\Theta$ c. 2, 1046a36-b3). 
[677] I - QUANTO À QUESTÃO

\section{A -Art. 1: Sobre a diferença assinalada}

9. Quanto a essa questão, ${ }^{83}$ mantendo que a diferença está bem assinalada, deve ser visto, primeiramente, de que modo ela deve ser entendida; e, em seguida, qual seja a causa dela.

\section{1 - De que modo a diferença deve ser entendida}

10. Sobre o primeiro [ponto], deve ser sabido que a potência ativa (de qualquer coisa que seja, seja [potência] de ação ou de um termo produzido [qualquer]) é de tal modo daquela [coisa] que, tendo permanecido a mesma natureza, ela não pode ser ativa de um [efeito] diferente daquele ao qual a partir de si tem poder. A frieza, pois, permanecendo frieza, não pode ser ativa do calor e nem produtiva do aquecimento, se não é de si ativa [dessa maneira]. Porque, qualquer [circunstância] que se fizesse acerca dela, mesmo que algum outro pudesse fazer alguma coisa para o existir do calor, [ainda assim] jamais a frieza [enquanto tal] atuaria para tanto.

11. Aquela potência ativa, portanto, é dita ser de [efeitos] opostos - seja de contrários seja de contraditórios - produzidos que, permanecendo uma única natureza, tem um termo primeiro sob o qual ambos os [efeitos] opostos podem igualmente cair. Mas é de ações opostas aquela [potência] que, permanecendo uma única [natureza], é o bastante para produzir tais ações. E se a ação da potência ativa propriamente for chamada de 'ato', assim como foi exposto na quarta questão, quanto ao terceiro argumento, ${ }^{84}$ então toda a [potência] que é de ações opostas é de atos opostos, não o contrário.

[678] 12. Isto, porém, deve ser entendido enquanto a potência for de ações opostas, ou da ação e da negação dela, como ficará evidente no segundo artigo ${ }^{85} \mathrm{E}$ é chamada esta 'potência ativa' não a própria relação que é enumerada segundo o número de correlativos, mas uma natureza absoluta, que é o próprio fundamento de muitas relações (que são para efeitos opostos).

\section{2 - Qual é a causa da diferença entre as potências}

13. Sobre o segundo [ponto], parece que Aristóteles considera como a causa da diferença [entre as potências] a seguinte: ${ }^{86}$ porque a forma natural é o princípio de

83 Cf. Duns Scotus, Lectura II, d. 25, q. un., n. 55. 60-68. 69-80 (XIX 247. 249-257); Additiones magnae II, d. 25, q. un. n. [22] (ed. Vivès XIII 222); Ordinatio I, d. 2, p. 2, q. 1-4, n. 347-352 (II 333-335); Quodl. q. 16, n. [118] (ed. Alluntis p. 581-609).

84 Cf. acima q. 3-4, n. 48-49.

85 Cf. abaixo n. 24-25. 31-34.

86 Aristot., Metaph. IX, t. 3 (AL XXV3 181; $\Theta$ c. 2, 1046b10-15): "Por isso [é] necessário também que tais ciências sejam de [efeitos] contrários, que, entretanto, sejam deste [membro contrário] de fato segundo si, do outro [membro contrário], entretanto, não segundo si... Pois, pela negação e retirada [o conceito] mostra o contrário; e, pois, a privação primeira [é] o contrário". 
assimilar exclusivamente um único oposto [diante de um par], por semelhança natural, assim como essa é essa, e não a oposta.

14. Porém, uma forma do intelecto, como, por exemplo, a ciência, é o princípio de assimilar opostos por uma semelhança intencional, assim como também essa mesma ${ }^{87}$ é virtualmente a semelhança de opostos conhecidos. ${ }^{88}$ Porque a mesma é a ciência de contrários assim como também de opostos privativamente, visto que um dos contrários inclui a privação do outro; porém, o agente é ativo [com respeito] àquilo que pode assimilar a si segundo a forma pela qual age; por isso mesmo, parece que Aristóteles põe a mencionada diferença [entre potências racionais e irracionais].

\section{Mas, essa razão é reprovada de muitas maneiras:}

Primeiramente, porque a forma natural pode ser o princípio de assimilar opostos virtualmente. [Isso] fica evidente sobre o sol.

16. Em segundo lugar, porque parece pôr somente o intelecto ou a [sua] ciência como [679] potência racional; e isso é falso, como será dito depois [Segue-se uma anotação interpolada: ver o Gandavense, na questão 7 do Quodlibet XI ${ }^{89}$ onde afirma que "'poder para contrários' pode ser entendido de muitas maneiras. De um modo, da parte dos objetos, que são bem e mal com respeito à vontade, verdadeiro e falso da parte do intelecto". E é certo que tanto a vontade quanto o intelecto são acerca de contrários, porque o intelecto [é acerca] do verdadeiro e do falso, etc. "Por outro modo, pode entender-se o 'poder para contrários' da parte dos atos". Mas, isto [pode ser tomado] duplamente, porque 'ou pode ser entendido que a potência tem poder para atos contrários com respeito a objetos contrários, ou com respeito ao mesmo objeto, tal como fugir do mal e buscar o bem em relação à vontade, assentir à verdade e dissentir da falsidade em relação ao intelecto'. E, por este modo, também a potência irracional pode ser para opostos. Pelo segundo modo, [tem-se] o poder para contrários, a saber, para atos contrários, como, por exemplo, fugir de a e não fugir de a em relação à vontade (ademais, buscar e não buscar a), em relação ao intelecto assentir e não assentir ao mesmo; assim, eu digo, 'poder para contrários' convém de si, ou a partir de si, somente à vontade, e ao intelecto [enquanto] se o comanda pela vontade.

87 Isto é, a ciência. N. do T.

88 A. B. Wolter, Translation, in: John Duns Scotus, A Treatise on Potency and Act - Questions on the Metaphysics of Aristotle Book IX, p. 367, assim complementa: "(...) is a virtual likeness of opposites [e.g. the medical science is knowledge of both health and sickeness], (...)".

89 Henricus Gand., Quodl. XI, q. 7 in corp. (459NO): "Deve ser dito que o poder para contrários pode ser entendido de muitas maneiras. Por um modo, da parte dos objetos que são o bem e o mal da parte da vontade, o verdadeiro e o falso da parte do intelecto... Por outro modo, é entendido o poder para contrários da parte dos atos acerca dos objetos contrários, tal como repelir o mal e buscar o bem da parte da vontade, assentir à verdade e dissentir à falsidade da parte do intelecto... Entendendo, portanto, os contrários deste modo, digo que toda substância intelectual tem poder para contrários, mas pela vontade somente, porque ela somente é livre e não determinável por nada ou determinada senão pelo sumo bem, inteligido inicialmente". 
E, por isso mesmo, somente a vontade é potência racional de maneira completa, potente para opostos]. ${ }^{90}$

17. Isto, ademais, ele parece pôr mais expressamente no capítulo $4,{ }^{91}$ onde conclui que a potência racional é de opostos; ela nada faria a não ser que fosse determinada a um daqueles [contrários], e aquilo que determina ele afirma ser "o desejo ou a prohairesis". ${ }^{92}$ Logo, parece que ele exclui aquela ${ }^{93}$ da razão de potência rational, na medida em que essa mesma é [potência] de opostos.

18. E isso mais expressamente fica evidente pelos trechos que seguem, ${ }^{94}$ onde [Aristóteles] parece dizer que a [potência] racional assim determinada necessariamente agiria, assim como também a [potência] irracional a partir de si age necessariamente. Portanto, parece simplesmente que não seja potência [680] racional aquele agregado de intelecto (que ele considera ser de opostos) e de desejo determinante (que ele considera [ser] necessário para que algo se faça).

19. Em terceiro lugar, não parece ser válida a prova que o intelecto seja de [efeitos] contrários, muito embora ele seja de [efeitos] opostos privativamente. Porque um contrário, ainda que inclua a privação do outro, não [o faz], contudo, precisamente, pois [aquele] é uma natureza positiva, e desse modo tem algum conhecimento próprio da sua entidade e não precisamente pelo outro oposto [conhecido]; por isso mesmo, ele é conhecido somente em sentido qualificado ${ }^{95}$ por meio do outro oposto [conhecido].

\section{B - Art. 2: Sobre a diferença em si}

\section{1 - Sobre a diferença entre natureza e vontade}

20. Quanto ao segundo artigo, portanto: primeiramente, deve ser visto da diferença mencionada em si, em segundo lugar sobre a intenção de Aristóteles acerca da mesma.

21. Sobre o primeiro [ponto] deve ser sabido que a primeira distinção da potência ativa é segundo o modo diverso de produzir uma operação: ${ }^{96}$ que, pois, [uma potência]

90 Cf. abaixo n. 41.

91 Aristot., Metaph. IX, t. 10 (AL XXV3 184; $\Theta$ c. 5, 1048a10-11): "Logo, [é] necessário que haja alguma outra coisa que [seja] dominante. Chamo isto, porém, de desejo [appetitum] ou de prohairesis".

$92 \mathrm{Ou}$, ainda, "o desejo ou a escolha deliberada". N. do T.

93 Isto é, a potência da vontade ou do desejo. N. do T.

94 Aristot., Metaph. IX, t. 10 (AL XXV3 184-185; $\Theta$ c. 5, 1048a11-16): "O que, pois, [a potência racional] desejará principalmente, isto ela fará, quando [isso] existir, para que ela possa [agir], e quando tiver se aproximado do [poder] passivo. Porque todo o que pode segundo a razão, quando deseja aquilo do que tem potência e tal como tem [potência], é necessário que faça isto. Ele tem, porém, [potência] de fazer, estando presente o [poder] passivo e comportando-se de determinado modo".

95 Traduzo a expressão "secundum quid" por "em sentido qualificado". N. do T.

96 A. B. Wolter, Translation, in: John Duns Scotus, A Treatise on Potency and Act - Questions on the Metaphysics of Aristotle Book IX, p. 371, assim complementa: “(...) [rather than from the objects they are concerned with], (...)". 
age acerca disso ou daquilo (posto que se distingue de algum modo), ou mostra uma distinção, [isso], contudo, não [se obtém] tão imediatamente. A potência, pois, não é comparada com o objeto acerca do qual opera a não ser mediante a operação que ela produz, e isto de um modo ou de outro.

22. Esse modo, porém, de produzir uma operação própria não pode ser, em gênero, senão duplo. Ou bem, pois, a potência a partir de si é determinada a agir, de modo que, no quanto é de si, não pode não agir quando não é impedida extrinsecamente. Ou ela não é a partir de si determinada, mas pode realizar este ato ou o ato oposto; [ela pode], ademais, agir ou não [681] agir. A primeira potência é comumente chamada de 'natureza', a segunda é chamada de 'vontade'.

23. Donde a primeira divisão dos princípios ativos é em natureza e [em] vontade, de acordo com o que Aristóteles, no Livro II da Física, ${ }^{97}$ põe duas causas moventes por acidente, o acaso, ${ }^{98}$ segundo a natureza, e a fortuna ${ }^{99}$ segundo o propósito ou a vontade.

24. Se, portanto, for procurada a causa desta diferença, por que, a saber, a natureza é tão-somente de um único [efeito] (isto é - de qualquer que seja ou de quaisquer que sejam - ela é determinadamente a partir de si daquele [efeito] ou daqueles [efeitos]), [e] a vontade, porém, é de [efeitos] opostos (isto é, [ela é] a partir de si indeterminadamente desta ação ou da [ação] oposta, ou da ação ou da não-ação), pode ser dito que não há nenhuma causa desta [diferença]. Assim como, pois, o efeito imediato é relacionado com a causa imediata por si e primeiramente, e sem causa intermediária - do contrário, ir-se-ia ao infinito -, assim também a causa ativa parece que se relaciona do modo mais imediato com a sua ação, enquanto produz essa mesma. E tampouco ocorre dar-se uma causa por que assim [a causa ativa] produz [a sua ação] a não ser porque ela é tal causa. Mas isto é [precisamente] aquilo cuja causa estava sendo procurada.

25. Assim como, portanto, o quente aquece porque [é] quente, tampouco essa proposição 'o quente aquece' é mediata, mas [é uma proposição] primeira no quarto modo de [predicação] por si, ${ }_{100}^{100}$ da maneira em que esta [proposição] 'o quente a partir de si aquece determinadamente' [é por si]. Semelhantemente [se dá com] essa [proposição] 'a vontade quer', bem como 'a vontade não quer determinadamente, por determinação necessária a partir de si'. ${ }^{101}$

\footnotetext{
${ }^{97}$ Aristot., Physica II, t. 57-59 (B c. 5-6, 197a32-b13).

98 Cf., no original, a expressão "casum" (de "casus"). N. do T.

99 Cf., no original, a expressão "fortunam" (de "fortuna"). N. do T.

$100 \mathrm{Cf}$. Thomas, Anal. post. I, lect. 10, n. 7 (I2 40b): "E em seguida quando ele diz 'Ademais, por um outro modo' etc., põe o quarto modo, segundo o qual esta preposição 'por' designa a relação da causa eficiente ou de qualquer outra [causa] extrínseca"; cf. Aristot., Anal. post. I, c. 4 (AL IV1 13; A c. 4, 73b10-11).

101 Cf. Duns Scotus, Ordinatio I, d. 8, p. 2, q. un., n. 299 (IV 324-325); Quodl. q. 16, n. [13-14] (ed. Alluntis, p. 601-604).
} 
[682] 26. Contra essas [coisas], objeta-se. Primeiramente, assim: essa proposição 'a vontade quer' é contingente. Se a vontade não é de si determinada para querer, de que modo alguma proposição contingente é imediata?

27. Em segundo lugar, assim: por que é posta essa indeterminação na vontade, se ela não pode ser provada pela natureza da vontade?

28. Quanto ao primeiro [argumento contrário], ${ }^{102}$ a resposta [é]: a partir do necessário não se segue o contingente, fica evidente. Tome-se uma [proposição] contingente. Se ela é imediata, tem-se o propósito [em questão]. Se ela não [o é], dê-se um mediato: a outra premissa para [chegar] àquela mesma [proposição] será contingente; do contrário, o contingente seria inferido a partir do necessário. [Mas], se aquela premissa contingente é mediata, [então] uma outra premissa em relação àquela [proposição] será contingente, e assim ao infinito, a não ser que se pare em alguma [proposição] contingente imediata.

29. Confirma-se: No Livro I dos Segundos analíticos, ${ }^{103}$ Aristóteles quer que ocorra o opinar 'por que', a saber, por meio de [proposições] imediatas, e [o opinar] 'que', por meio de [proposições] mediatas. Desse modo no propósito [em questão], 'a vontade quer a'. Se não há causa entre os extremos, tem-se o propósito [em questão]. Se há causa, como, por exemplo, 'a vontade quer b', procedendo-se mais além parar-se-á em algum lugar. Onde? Por que a vontade quer aquilo? Não há nenhuma outra causa senão que [a vontade] é a vontade. E, contudo, se aquela última proposição fosse necessária, não antecederia sozinha uma [proposição] contingente.

30. Com relação ao segundo [argumento contrário], ${ }^{104}$ prova-se a posteriori. Pois, 0 que quer, experimenta [683] que pode não querer, ou desquerer, ${ }^{105}$ segundo o que se obtém mais expansivamente alhures sobre a liberdade da vontade. ${ }^{106}$

31. [Sobre a indeterminação de insuficiência e de suficiência] - Em segundo lugar, ${ }^{107}$ duvida-se acerca do que foi dito anteriormente, [a saber], de que modo tal causa

102 Cf. acima n. 26.

${ }^{103}$ Aristot., Anal. post. I c. 33 (AL IV 1 66; A c. 33, 89a21-22); cf. Robertus Grossatesta, Anal. post. I c. 19 (ed. P. Rossi p. 283): "Opina, com efeito, tanto que ["quia"] quanto por que ["propter quid"], se conhece por [proposições] imediatas; se, no entanto, não conhece por [proposições] imediatas, opinará somente que ["quia"]".

$104 \mathrm{Cf}$. acima n. 27.

105 Cf., no original, "Experitur enim qui vult se posse non velle, sive nolle, (...)". Uso, nesta tradução, "desquerer", "não-querer", "não-volente", e formas derivadas, para o verbo latino "nolle". Ele expressa uma volição negativa, mas de qualquer modo uma volição real ou exercitada. Deve ser diferenciado de "non velle", ou "não querer", e formas derivadas, porque essas fariam referência ao fato de o querer ou a volição não chegar a se realizar. Com "desquerer" ou "não-querer", quero apreender a unidade dessa volição negativa. De fato, o verbo "desquerer", em língua portuguesa, significa lexicalmente "deixar de querer", "não amar". Porém, ligado ao significado ora explanado, parece-me menos artificial do que uma forma verbal composta hifenizada. N. do T.

106 Cf. Duns Scotus, Lectura I d. 39 q. 1-5 n. 54 (XVII 497); Ordinatio, IV, d. 49, q. 10, n. [10] (ed. Vivès XXI 333); Quodl. q. 16, n. [1-18] (ed. Alluntis p. 581-609).

107 Cf. acima n. 24. 
será reduzida ao ato se é indeterminada de si para agir e não agir. - Resposta: há uma certa indeterminação de insuficiência, ou a partir de potencialidade e de defeito de atualidade, assim como a matéria que não tem forma é indeterminada para realizar uma ação da forma; há uma outra [indeterminação] de suficiência superabundante, que consiste de ilimitação de atualidade, seja pura e simplesmente ou de um determinado modo.

32. Pelo primeiro modo, o indeterminado não é reduzido ao ato a não ser que anteriormente seja determinado à forma por um outro; pelo segundo modo, o indeterminado pode se determinar. Se, pois, isto seria possível se houvesse ato limitado, quanto mais se [houvesse ato] ilimitado, visto que então não careceria de nada que foi simplesmente um princípio de agir? De outro modo, Deus, que é sumamente indeterminado a toda e qualquer ação por uma indeterminação de ilimitação, não poderia realizar algo; e isso é falso.

33. Exemplo disto: o fogo é calefativo, e nem se procura um extrínseco pelo qual ele seja determinado a agir. Se, então, não tendo sido feita nenhuma diminuição na perfeição do calor, fosse dada a ele a perfeição da frieza, por que desse modo a partir de si não poderia determinar-se para aquecer, como anteriormente? Aquele exemplo, contudo, não é totalmente semelhante, assim como será dito ao se responder ao argumento principal. ${ }^{108}$

34. Porém, a indeterminação que é posta na vontade não é [684] material, nem [indeterminação] de imperfeição enquanto essa mesma é ativa, mas é [indeterminação] de perfeição excelente e de poder, ${ }^{109}$ não estando presa para determinar um ato.

\section{2 - Sobre a intenção de Aristóteles}

35. Mas, de que modo se comportam as coisas anteriormente ditas com o que é intencionado por Aristóteles ${ }_{1}^{110}$ que não põe a mencionada diferença entre natureza e vontade, mas entre potência irracional e racional, entendendo por [potência] racional o intelecto somente, tal como parece de acordo com o que foi alegado acima? ${ }^{111}$

36. Resposta: o intelecto e a vontade podem ser comparados com os atos próprios que eles produzem, ou com os atos de outras potências inferiores, nas quais têm uma determinada causalidade: o intelecto [tem causalidade] mostrando e dirigindo,

\footnotetext{
108 Cf. abaixo n. 43.

109 Cf., no original, a expressão "potestativae". Cf. também C. González Ayesta, in: Juan Duns Escoto, Naturaleza y voluntad, Quaestiones super libros Metaphysicorum Aristotelis, IX, q. 15, p. 49: "(...), sino que es excelente en perfección y poder, no ligada a um acto determinado".

$110 \mathrm{Cf}$ acima n. 20.

111 Cf. acima n. 16-18.
} 
a vontade [tem causalidade] inclinando e comandando. A primeira comparação é a mais essencial, [como] fica evidente. E, assim, o intelecto cai sob a natureza. Ele é, pois, de si determinado a inteligir, e não tem em seu poder 0 inteligir e o nãointeligir, ${ }^{112}$ ou [ainda], acerca de complexos, onde pode ter atos contrários, [0 intelecto] não tem ademais aqueles [contrários] em seu poder: assentir e dissentir. $\mathrm{Na}$ medida em que, ademais, um conhecimento é de opostos conhecidos, como Aristóteles parece dizer, ${ }^{113}$ então, com respeito àquela cognição, o intelecto não é de si indeterminado; antes, necessariamente produz aquela intelecção, assim como uma outra [intelecção] que fosse tão-somente de um único [685] conhecido. A vontade, como foi dito anteriormente, ${ }^{114}$ relaciona-se de modo oposto com 0 ato próprio. - Donde, falando-se desse modo, põem-se tão-somente duas produções na realidade divina, ${ }^{115}$ e [considera-se] que o intelecto é um princípio idêntico com a natureza. - Segundo esta primeira comparação, Aristóteles não parece falar [nada].

37. A segunda comparação ${ }^{116}$ parece como que acidental. Tanto porque com os atos de outras potências [por elas controladas] essas potências, [a saber, intelecto e vontade], não são comparadas senão mediante atos próprios, como parece, atos próprios esses que são anteriores àqueles outros [atos]; quanto porque, especialmente, o intelecto, por este modo, não possui a razão de potência ativa propriamente dita; [isso] foi tocado no capítulo 6 da questão 2 do Livro VII. ${ }^{117}$

38. E deste modo Aristóteles parece falar e pôr tal ordem, pois primeiramente é requerido algum conhecimento dos opostos. Mas, esse [conhecimento], de si, é insuficiente para causar algum [efeito] para fora, porque, como [Aristóteles] argumenta no capítulo $4,{ }^{118}$ ele então produziria opostos. Isto não parece se seguir senão porque o intelecto (também cognoscente de opostos), quanto àquele [aspecto] de causalidade que tem com respeito àquelas coisas que devem ser feitas exteriormente, é de si determinado para aquilo do que é [a causa]. E dessa maneira [quanto à causalidade acerca de coisas exteriores] não somente não é racional com respeito ao ato próprio, mas tampouco [é] completamente racional com respeito ao ato extrínseco no qual é diretivo. Antes, precisamente tomado, também com respeito ao extrínseco, [o intelecto] é irracional; porém, de um único modo, num sentido

112 Isto é, acerca de incomplexos.

$113 \mathrm{Cf}$. acima n. 2.

$114 \mathrm{Cf}$ acima n. 22-34.

115 Cf. Duns Scotus, Lectura, I, d. 2, p. 2, q. 1-4, n. 202-205 (XVI 183-186); Ordinatio, I, d. 2, p. 2, q. 1-4, n. 300-303 (II 305-309). A. B. Wolter, Translation, in: John Duns Scotus, A Treatise on Potency and Act Questions on the Metaphysics of Aristotle Book IX, p. 379, assim complementa: "(...) [namely, that of the Word and that of the Holy Spirit] (...)". N. do T.

${ }^{116}$ A saber, a vontade com respeito aos atos de outras potências inferiores.

${ }^{117}$ Nada sobre isso, como parece, consta na questão 2 do Livro VII de Scotus; veja-se, contudo, a questão 2 do Livro VI, n. 27-28. 32.

${ }^{118}$ Aristot., Metaph. IX, t. 10 (AL XXV3 184; $\Theta$ c. 5, 1048a8-10): "Pois, com efeito, todas estas [potências irracionais] [são] capazes de fazer uma única [atividade], aquelas [potências racionais], porém, [são capazes de atividades] contrárias, porque ao mesmo tempo farão contrários, [mas] isto, porém, [é] impossível". 
qualificado [ele é] racional, [a saber], enquanto é pré-exigido para o ato de uma potência racional.

[686] 39. Segue-se a vontade determinante, não assim que essa potência da vontade de si seja determinada a um único [efeito] - e por meio disto o agregado do intelecto de [efeitos] opostos e da vontade seja de um único [efeito], como é alegado aci$\mathrm{ma}^{119}$-, mas que a vontade, que é indeterminada para 0 ato próprio, produz aquele [ato] e por meio daquele [ato] determina o intelecto quanto àquela causalidade que ele tem com respeito ao realizar para fora. ${ }^{120}$

40. Donde Aristóteles diz:121 "isto, porém, chamo de desejo, ou prohairesis", isto é, a escolha; ele não chama, porém, de vontade, a saber, uma potência. E desse modo, se a potência racional for chamada por Aristóteles de intelecto, a diferença mencionada [entre potência racional e potência irracional] deve ser entendida assim, segundo o que foi exposto acima: ${ }^{122}$ a [diferença] não convém ao [intelecto] com respeito ao [seu] ato próprio, nem enquanto ele, por um ato seu, concorre com um ato de uma potência inferior, tomando-se precisamente o seu ato, mas, em ambos os modos, ele cai sob a natureza. Porém, ela cai sob o outro membro [da distinção, a saber, a potência racional da vontade], enquanto ele, pelo seu ato, [é] prévio aos atos da vontade.

41. Se, porém, entende-se "racional" como "com a razão", então a vontade é propriamente racional. E ela é de opostos, tanto em relação ao ato próprio quanto em relação aos atos das [potências] inferiores [que ela controla]; e [ela] não [é] de opostos pelo modo da natureza, assim como o intelecto que não pode se determinar a um outro [efeito], mas por um modo livre [assim como uma] que pode determinar a si. E por isso mesmo ela é potência, porque ela pode algo, pois pode determinar a si. Porém, o intelecto não é propriamente uma potência com respeito a coisas extrínsecas, porque ele mesmo, se é de opostos, não [é] um que pode determinar [a si]; e a não ser que seja determinado não tem poder [de fazer] nada para fora.

\section{[687] $\mathrm{C}$ - Resposta às objeções contra a via de Aristóteles}

42. Por meio do que foi dito, pode ser respondido àquelas [objeções] que são alegadas acima contra a via de Aristóteles.

43. Quanto ao primeiro [argumento contrário], ${ }^{123}$ sobre o sol, respondo: a forma natural, se é ilimitada e um princípio de [efeitos] opostos nas matérias dispostas daqueles, é tão determinadamente como aquela [forma] que é de um único [efeito]

\footnotetext{
119 Cf. acima n. 18.

120 Cf. Duns Scotus, Ordinatio, II, d. 42, q. 4, n. [10-11] (ed. Vivès XIII 460-461).

${ }^{121}$ Aristot., Metaph., IX, t. 10 (AL XXV2 173; $\Theta$ c. 5, 1048a10-11); cf. acima n. 17.

$122 \mathrm{Cf}$. acima n. 38-39.

$123 \mathrm{Cf}$. acima n. 15
} 
[é] tão-somente daquele [efeito] determinadamente. Pois não está em seu poder agir para uma ou outra dessas formas, em estando presente o passivo receptivo desta forma e daquela, assim como tampouco estaria [em seu poder] se fosse de uma única [forma] tão-somente. A vontade, porém, da sua ação, seja acerca deste oposto ao qual tem poder ou acerca daquele, não é um princípio de si determinado, mas [um princípio] determinativo de si em termos de poder ${ }^{124}$ para um ou outro [efeito oposto]. E por meio disto fica evidente de que modo é deficiente a semelhança colocada acima sobre o calor e o frio contidos unitivamente num mesmo [agente]; ${ }^{125}$ e, para ser breve, tampouco algum exemplo conveniente pode ser completamente aduzido, porque a vontade é um princípio ativo distinto em contraposição ao gênero dos princípios ativos que não são a vontade, pelo [seu] modo oposto de agir.

44. E, por isso mesmo, parece bastante tolo aplicar à vontade proposições universais sobre o princípio ativo, pelo fato de que não se têm instância [sobre o modo como ela opera] em algo diferente da [própria] vontade. Só ela, pois, não é esse tipo [de princípio ativo submetido a tais proposições universais]. E tampouco, por isso mesmo, deve ser negado que ela é tal porque uma outra [coisa] não é tal. Porque o princípio ativo criado é capaz, sem contradição, daquela perfeição que atribuímos à vontade, a saber, que não somente não seria determinado a um único efeito ou ato, porque tem muitos [efeitos] em [sua] [688] virtude, mas tampouco é determinado a algum daqueles [efeitos] que tem em suficiente virtude. Quem, pois, nega que um [princípio] ativo é mais perfeito quanto menos [é] dependente, determinado e limitado com respeito ao ato ou ao efeito? E se isto é concedido da ilimitação a muitos e contrários efeitos, [mesmo], contudo, com a determinação natural ${ }^{126} \mathrm{com}$ respeito a qualquer um daqueles [efeitos], quanto mais se com a primeira indeterminação é posta também a segunda? ${ }^{127}$ Pois, esta contingência é mais nobre do que a necessidade, assim como foi tocado na questão erguida do Livro V, no capítulo 'Sobre o necessário', ${ }^{128}$ a saber, de que modo é de perfeição em Deus nada causar necessariamente. Logo, se essa perfeição que atribuímos à vontade não é incompatível com o princípio ativo criado, e tal [princípio] sumo é a vontade, [então], racionalmente, ela deve ser atribuída a ela. ${ }^{129} \mathrm{E}$ essa exposição é melhor do que aquela colocada anteriormente sobre o calor e o frio combinados. ${ }^{130}$

45. Segundo isto, aquela razão que parece ser posta no texto ${ }^{131}$ pode ser investigada assim: se o intelecto, pelo mesmo conhecimento, é de algum modo de opostos, como

124 Cf., no original, a expressão "potestative determinativum sui". N. do T.

$125 \mathrm{Cf}$. acima n. 33.

${ }^{126}$ A. B. Wolter, Translation, in: John Duns Scotus, A Treatise on Potency and Act - Questions on the Metaphysics of Aristotle Book IX, p. 385, assim complementa: "(...) [like the sun], (...)". N. do T.

${ }^{127}$ Cf. acima n. 31-32. Trata-se, no segundo caso, da indeterminação de suficiência superabundante. N. do T.

128 Cf. Duns Scotus, Opera Philosophica III - Quaestiones super libros metaphysicorum Aristotelis Libri VI-IX, in: R. Andrews et alii (eds.), St. Bonaventure, Franciscan Institute Publications, 1997, V, q. 3, n. 26-29.

129 Isto é, à vontade. N. do T.

$130 \mathrm{Cf}$ acima n. 33.

$131 \mathrm{Cf}$ acima n. 2. 
um que mostra [esses opostos à vontade], logo uma potência ativa [ainda] mais indeterminada pode ser de [efeitos] opostos num modo [ainda] mais excelente pelo modo de opostos, a saber, enquanto ela mesma, existindo una, pode determinar a si a ambos aqueles [opostos] mostrados [a ela]. De outro modo, em vão pareceria ter sido dada a potência primeira de opostos, porque essa, sem uma segunda [potência, como a vontade], não teria poder para nenhum daqueles [opostos], de modo que 0 argumento se dá a minori, ${ }^{132}$ e não por uma causa própria; o conhecimento estrito, pois, não é a causa própria da diferença anteriormente mencionada.

[689] 46. Em relação ao segundo [argumento contrário]: ${ }^{133}$ Aristóteles não exclui a vontade da potência racional, a não ser enquanto a potência racional é tomada de modo incompleto, a saber, pelo conhecimento de opostos. Mas, ele afirma que essa [potência] incompleta não é a causa de coisa alguma extrínseca senão por uma determinação realizada por uma outra parte. Pergunto: pelo que se dá a determinação pela eleição? Não [se dá] senão por uma potência que elege, e isto enquanto ela é distinguida em relação à razão. A razão, pois, não é determinativa, visto que é de opostos com respeito aos quais ela não pode determinar [a si], e muito menos [determinar] algo diferente de si. Ou, [então], se determinasse a si, isto se daria ao mesmo tempo com relação a [efeitos] opostos, assim como Aristóteles argumenta sobre 0 agir. ${ }^{134} \mathrm{E}$ aquele outro [elemento, que não a razão], não se determina necessariamente a esse oposto, porque, nesse caso, o intelecto nem em potência remota seria [uma potência] de opostos. Portanto, aquele outro [elemento distinto da razão] contingentemente determina a si, e, quando por meio de um ato seu tiver se determinado, conseqüentemente determina o intelecto.

47. Aristóteles, portanto, dá a entender que aquela potência é a partir de si de [efeitos] opostos, tal que [é] determinativa de $\mathrm{si}^{135}$ a um ou outro [dos opostos]; por meio do ato dela já evocado determinadamente, [Aristóteles] considera que aquela [potência do intelecto] é determinada com respeito às obras exteriores, [potência essa] que era a partir de si de tal modo de [efeitos] opostos que necessariamente não podia se determinar. E desse modo, mostrando no capítulo 4 de que modo a potência racional incompleta procede para o ato, [o Filósofo] parece manifestamente dar a entender que há uma outra [potência] racional completa, no que diz respeito a essa diferença aqui posta, ${ }^{136}$ e que aquelas duas [potências, do intelecto e da vontade], concorrem com os seus atos [próprios] com respeito ao efeito exterior,

$132 \mathrm{Ou}$, por uma causa menor. Cf. A. B. Wolter, Translation, in: John Duns Scotus, A Treatise on Potency and Act - Questions on the Metaphysics of Aristotle Book IX, p. 385: "In this way, the argument rests on the dialectical rule a minori, and would not be an instance of reasoning from a proper cause, (...)". N. do T.

${ }^{133} \mathrm{Cf}$ acima n. 16-18.

${ }^{134}$ Aristot., Metaph., IX, t. 10 (AL XXV3 185; $\Theta$ c. 5, 1048a21-24): "E por causa disso, nem se ao mesmo tempo querem ou desejam fazer duas coisas ou contrários, não farão; pois não [é] desse modo que ao mesmo tempo têm potência para tanto, e nem há uma potência de fazer simultaneamente".

$135 \mathrm{Ou}$, mais simplesmente, "autodeterminante", "autodeterminativa"; cf., no original, a expressão "determinativa sui". N. do T.

136 Isto é, no capítulo 5 do Livro IX da Metafísica; cf. acima nota 91 e n. 17. N. do T. 
[efeito] com respeito ao qual não há potência [690] de contradição propriamente na potência executiva, a qual é racional por participação. Mas, a razão total de potência para opostos reside formalmente na vontade.

48. Porém, o que Aristóteles acrescenta, ${ }^{137}$ [isto é], que a [potência] racional, assim determinada, necessariamente é de um [efeito], [em que] "o que deseja principalmente, isto fará": poderia ser dito que [isso] não é verdadeiro de necessidade absoluta. Assim como, pois, o antecedente, se é antecedente, a saber, "querer aquilo", não é necessário, desse modo tampouco o conseqüente [é necessário]. Se [o ato da vontade] se dá necessariamente, [então] o conseqüente, a saber, aquele fazer exterior, é necessário. Se, porém, segue-se necessariamente '[a vontade] quer este [item] extrínseco; logo, não impedido [o querer], faz isto', então Aristóteles não poria nenhum efeito senão [aquele que é feito] por uma causa determinada a esse mesmo antes - antes por natureza - que produza esse mesmo; excetua-se somente o querer, que segue a apreensão de opostos e determina, segundo ele mesmo, ${ }^{138}$ com respeito aos [efeitos] que seguem para fora.

49. Assim poderia ser exposto aquilo que está no final do capítulo 4: ${ }^{139}$ Por causa disso nem se [ao mesmo tempo a vontade] quer opostos necessariamente fará, etc. Porque, pois, isto não se segue da vontade? E, contudo, ele argumenta anteriormente, no princípio, no capítulo 'Sobre a potência racional', ${ }_{140}$ que essa [capacidade] "fará ao mesmo tempo" parece uma boa diferença [dela com respeito a uma potência irracional]; porque assim fará tal como ela tem potência de fazer, porém, não [fará de uma só vez] tal como tem potência de fazer.

50. Porém, a potência racional incompleta, ela a partir de si, como foi dito, ${ }^{141}$ é natural com respeito aos [seus] opostos. Por isso mesmo, no quanto é de si, não [691] somente [será capaz] ao mesmo tempo de opostos, mas também [capaz] de [produzir] opostos

${ }^{137}$ Aristot., Metaph., IX, t. 10 (AL XXV3 184-185; $\Theta$ c. 5, 1048a11-15): "O que, pois, [a potência racional] desejará principalmente, isto ela fará... Porque todo o que pode segundo a razão, quando deseja aquilo do que tem potência e tal como tem [potência], é necessário que faça isto".

138 Isto é, segundo Aristóteles. N. do T.

139 Aristot., Metaph., IX, t. 10 (AL XXV3 185; $\Theta$ c. 5, 1048a21-24): "E por causa disso, nem se ao mesmo tempo querem ou desejam fazer duas coisas ou contrários, não farão; pois não [é] desse modo que ao mesmo tempo têm potência para tanto, e nem há uma potência de fazer simultaneamente, visto que daquilo do que há [potência] assim ele fará"; eis o texto de Aristóteles na exposição de Antônio André (ed. Vivès VI 329b): "E por causa disso, nem se ao mesmo tempo querem ou são desejados fazer duas coisas ou contrários, farão. Pois não [é] desse modo que ao mesmo tempo têm potência para tanto, e nem há uma potência de fazer simultaneamente, visto que daquilo do que há [potência] assim farão"; não teve Scotus um texto corrompido de Aristóteles quando alegou " $\mathrm{E}$ por causa disso nem se quer opostos necessariamente fará"?

140 Aristot., Metaph. IX, t. 10 (AL XXV3 184; $\Theta$ c. 5, 1048a8-10): "Pois, com efeito, todas estas [potências irracionais] [são] capazes de fazer uma única [atividade], aquelas [potências racionais], porém, [são capazes de atividades] contrárias, porque ao mesmo tempo farão contrários, [mas] isto, porém, [é] impossível".

141 Cf. acima n. 36, 41, 46-47. 
ao mesmo tempo ${ }^{142} \mathrm{E}$, por isso mesmo, se essa [potência] a partir de $\mathrm{si}^{143}$ produzisse aqueles, ao mesmo tempo [os] produziria. Assim como o sol é de [efeitos] opostos ao mesmo tempo em [sujeitos] receptivos diversos, e ao mesmo tempo [os] produziria, tendo eles sido aproximados. E se fosse daqueles [efeitos opostos] em igual medida, e tão-somente um mesmo [objeto] igualmente passivo, receptivo de ambos [os efeitos opostos], fosse aproximado ao [sol], [o sol] nada faria [a ele], ou [produziria] simultaneamente naquele [objeto efeitos] opostos: desse modo [ocorre] aqui.

51. Contra: o intelecto não é igualmente de [efeitos] opostos; logo, ele agiria segundo a virtude mais forte. - Resposta: [em verdade], por meio de um único conhecimento, que é de um hábito e de uma privação, [o intelecto] não é igualmente desses [efeitos opostos]; mas, [ele é] de um por si, do outro por acidente. Mas, por dois conhecimentos positivos de contrários, [o intelecto] pode ser a causa de opostos.

52. Contra: de que modo é válida a conseqüência de Aristóteles sobre o 'não em mesma medida'? ${ }^{144}$ - Não [é] assim, porém, sobre a vontade. Se, pois, [ela] é de opostos virtualmente, simultaneamente ela [é] deles, mas ela não [é] deles simultaneamente. Afinal, ela não é deles no modo de natureza, mas podendo se determinar a um ou outro [efeito] antes do [efeito], e, por isso mesmo, [ela] fará dessa maneira.

Deste modo, talvez, poderia ser exposto o capítulo 4, que muito seria a favor da vontade, ainda que algo, ali, pareça contra a vontade.

53. Mas, contra: por que, em verdade, tão freqüentemente chama o intelecto de potência racional, e não a vontade, ainda que dê a entender [o inverso] segundo o que foi dito anteriormente?

[692] Pode ser dito que o ato do intelecto é comumente prévio ao ato da vontade, e mais conhecido a nós. Aristóteles falou mais freqüentemente sobre o que é mais manifesto, donde sobre a vontade encontra-se pouco do que tenha dito, ainda que a partir do que foi dito por ele algumas coisas se sigam nas quais teria falado nesse sentido, caso as tivesse considerado.

54. O terceiro [argumento], ${ }^{145}$ introduzido contra Aristóteles, conclui o verdadeiro, a saber, que o conhecimento de apreensão simples de ambos os contrários é próprio a [cada um] deles e [é] por espécie própria. Pelo conhecimento discursivo, contudo, visto que [ali] um [item] é anterior por natureza ao outro, pode haver algum princípio

142 Cf. Duns Scotus, Lectura, II, d. 25, q. un. n. 36-37 (XIX 239-240); Ordinatio I, d. 2, p. 2, q. 1-4, n. 346-351 (II 333-335); Rep. II, d. 25, q. un. ad 4, n. [23] (ed. Vivès XXIII 129); Additiones magnae II, d. 25, q. un., n. [10. 25] (ed. Vivès XII 205. 224).

143 Isto é, sem a vontade. N. do T.

${ }^{144}$ Cf. Aristot., Metaph. IX t. 3 (AL XXV2 170; $\Theta$ c. 2, 1046b4-6); Auctoritates Aristotelis (ed. J. Hamesse, p. 134): "A potência racional é capaz de opostos, a [potência] irracional, entretanto, [é capaz] tão-somente de um [efeito]".

145 Cf. acima n. 19. 
de conhecimento daquilo. E assim pode ser exposto aquele [dito] no Livro I de Sobre a alma, ${ }^{146}$ [a saber], "a [linha] reta é juiz do [conhecimento] de si e do curvo". 0 juízo, pois, não pertence à apreensão simples, mas à comparação de [itens] complexos. Quanto, pois, ao conhecimento num sentido qualificado, ${ }^{147}$ um pode, por uma simples apreensão, ser apreendido pela espécie de outro, a saber, quanto à privação que inclui, não, com efeito, dentro da essência ou da razão essencial do [outro], mas concomitantemente.

55. Portanto, pelo primeiro modo, [isto é, pelo conhecimento de simples apreensão], o conhecimento é o mesmo dos contrários, de um [contrário] formalmente e do outro virtualmente, assim como [o conhecimento formal] do princípio e [o conhecimento virtual] das conclusões. ${ }^{148} \mathrm{E}$ se alguma volição, como, por exemplo, a escolha, talvez, exige previamente um juízo sobre o que deve ser eleito, um dos contrários pode ser conhecido por meio do outro em relação àquele conhecimento, muito embora se escolha, às vezes, contra aquele juízo.

[693] 56. Pelo segundo modo, [isto é, pelo conhecimento discursivo], é o mesmo o conhecimento de contrários, de um [contrário é] num sentido qualificado, do outro [é] simplesmente. E aquele [conhecimento] basta para que a vontade queira um ou outro dos contrários, enquanto ele é mostrado [a ela] por aquele conhecimento. E, assim, ela é capaz de [efeitos] contrários; logo, também [pode querer contrários] simplesmente, porque eles não são incompatíveis [um com o outro] absolutamente, a não ser talvez pela razão de tal privação; ${ }^{149}$ ou não [é] na razão [de privação] [que eles são algo] querível, como parece, porque ambos parecem queríveis enquanto [algo] positivo.

57. Se for dito que "a potência racional é capaz de opostos"150 somente se não for determinada a um único, e que de outro modo não [seria capaz de opostos]: - Contra: a partir disto segue-se que não há uma diferença entre as potências racionais e as irracionais quanto àquilo que é poder para opostos. $O$ conseqüente [é] falso a partir desse Livro IX da Metafísica; ${ }^{151}$ logo, [também] o antecedente [é falso].

58. Prova da conseqüência: a potência irracional, tanto a ativa quanto a passiva, enquanto é anterior por natureza ao ato determinante, tem poder para [efeitos] opostos, como fica evidente por Aristóteles, no Livro II de Sobre a interpretação, ${ }^{152} \mathrm{e}$

146 Aristot., De an. I, t. 85 (A c. 5, 411a4-5); Auctoritates Aristotelis (ed. J. Hamesse p. 176): "a [linha] reta é juiz do [conhecimento] de si e do curvo".

147 Cf., no original, a expressão "secundum quid". N. do T.

148 Aristot., Anal. post. I, c. 1 (AL IV1 6; A c. 1, 71a24-29); Thomas, Anal. Post., I, lect. 3, n. 1 (I 146b).

149 Isto é, no sentido de que um contrário é a privação do outro. N. do T.

150 Aristot., Metaph. IX, t. 3 (AL XXV2 170; $\Theta$ c. 2, 1046b4-6; t. 10 (AL XXV2 173; @ c. 5, 1048a7-9); Auctoritates Aristotelis (ed. J. Hamesse p. 134): "A potência racional é capaz de opostos, a [potência] irracional, entretanto, [é capaz] tão-somente de um [efeito]".

151 Aristot., Metaph. IX, t. 3 (AL XXV2 170; $\Theta$ c. 2, 1046b4-6; t. 10 (AL XXV2 173; c. 5, 1048a7-9).

152 Aristot., De interpr. II, c. 13 (AL II1 32; c. 13, 23a4-5): “(...), entretanto, também no que tange potências irracionais algumas têm poder simultaneamente para determinados [efeitos] opostos". 
por Boécio, no Livro VI do comentário sobre a mesma [obra], na edição segunda, ${ }^{153}$ onde põe o exemplo sobre a água, que pode esfriar e aquecer.

59. Ademais, se ela não tivesse poder para opostos quando é determinada em ato [a um dos efeitos], isto é, naquele instante e para aquele [instante], nenhum efeito que é em ato seria contingente em ato. $O$ conseqüente é falso; logo, [também] 0 antecedente [é falso]. A falsidade do conseqüente [694] fica evidente pelo Filósofo, no Livro I de Sobre a interpretação, ${ }^{154}$ onde ele quer que esta proposição seja necessária: "Tudo o que é, quando é, é necessário que seja", porque algo existe contingentemente. Prova da conseqüência: um efeito não é chamado de contingente em potência a não ser por razão da sua causa que tem poder para o oposto; logo, nem em ato um efeito [seria] contingente a não ser que a causa que causa atualmente tivesse poder para um oposto naquele agora no qual causa esse [outro oposto]. Mas, para ti, então ${ }^{155}$ [a potência] não tem [tal] poder, visto que então ${ }^{156}$ é determinada; logo, [etc.].

60. Caso digas 'o efeito é dito contingente porque [naquele momento anterior à volição ainda] pode não se realizar', ${ }^{157}$ contra: anteriormente [àquele momento] não foi um ente; logo, nem anteriormente [foi] um efeito contingente em ato. Agora, pois, falamos da contingência conforme é um modo do ente em ato, quando é em ato, e naquele agora no qual é em ato.

61. Ademais, o que convém a algo ${ }^{158}$ por si e primeiramente, o oposto dele não convém [a ele] por si e nem por acidente, em permanecendo aquele mesmo [predicado]. De outro modo, a demonstração pelo porquê, ${ }^{159}$ concluindo uma propriedade do sujeito, não seria a partir de [premissas] necessárias. Mas, o poder para opostos convém à potência racional segundo si e primeiramente, enquanto uma propriedade própria da potência racional enquanto racional, pois por isto ela é distinguida da [potência] irracional, de acordo com o Livro IX da Metafísica; ${ }^{160}$ logo, etc.

153 Boethius, In De Interpr. [ed. secunda] VI c. 13 (ed. Meiser 451; PL 64, 615): "E essas [potências], entretanto, não são segundo a razão, embora existam determinadas [potências] que são capazes de opostos, não contudo todas. Pois com a água ter-se-á um poder refrigerador que é irracional, e nela, por outro lado, um outro poder de aquecer, quando ela mesma estiver aquecida, mas isto não pode ser encontrado em todos os poderes irracionais".

154 Aristot., De interpr. I, c. 9 (AL II1 17; c. 9, 19a23-24); Auctoritates Aristotelis (ed. J. Hamesse p. 306): "Tudo o que é, quando é, é necessário que seja".

155 O sentido de "então" ["tunc"], aqui e adiante, no período, é o de "naquele tempo", "naquela ocasião" ou, ainda melhor, "naquele agora" ou "naquele instante de tempo", como antes alegado. N. do T.

${ }^{156}$ Literalmente, "naquele então" ["pro tunc"] ou, melhor ainda, "naquele agora" ou "naquele instante de tempo". N. do T.

157 Aqui, sigo basicamente A. B. Wolter, Translation, in: John Duns Scotus, op. cit., p. 397: “(...) to be contingent because [at that moment prior to such a decision, one could say] it could have not happened, (...)". N. do T.

158 Isto é, a um sujeito. N. do T.

159 Cf., no original, a expressão "demonstratio propter quid". N. do T.

${ }^{160}$ Aristot., Metaph. IX t. 3 (AL XXV2 170; $\Theta$ c. 2, 1046b4-6); t. 10 (AL XXV2 173; $\Theta$ c. 5, 1048a7-9). 
62. Ademais, Deus pode não predestinar o predestinado naquele e para aquele agora no qual ${ }^{161}$ predestinou, não obstante a determinação da sua vontade para 0 ato de predestinar, ${ }^{162}$ segundo todos [os teólogos]. Logo, a determinação $0^{163}$ não tolhe 0 'poder para opostos'.

\section{[695] II - Quanto aos argumentos principais}

\section{Quanto aos argumentos principais.}

Quanto ao primeiro [argumento], ${ }^{164}$ fica evidente que uma potência [racional], tal como a vontade é dita ser, é de contrários que devem ser feitos não ao mesmo tempo, mas ela pode determinar a si a um ou a outro [dos efeitos contrários]; não [é] assim [que opera] o intelecto. ${ }^{165}$

64. Quando se argumenta contra 'se posso não me sentar agora, em se supondo que eu esteja sentado?', digo que, no sentido de composição, a proposição de possibilidade, ${ }^{166}$ compondo os opostos, é falsa, porque indica que a potência é para opostos simultaneamente. ${ }^{167}$ No sentido de divisão, diriam alguns ${ }^{168}$ que, quando 0 sentar-se se dá, dá-se necessariamente, segundo aquele [princípio] no Livro I de Sobre a interpretação: ${ }^{169}$ "Tudo o que é, quando é", ${ }^{170}$ etc., e nada então ${ }^{171}$ [é] possível, mas tão-somente no instante anterior, no qual o agora podia não haver de ser. $\mathrm{E}$ esses não vêem que podem manter que a vontade agora é uma potência para o oposto daquilo que se dá. Há absurdidade nesta posição, que, a saber, não sejam a necessidade e a contingência as condições próprias dos entes, quando existem, mas tão-somente a necessidade, e jamais a contingência, porque, quando [o ente] não é, nem é necessariamente nem contingentemente. De que modo, porém, aquela autoridade no Livro I [de Sobre a interpretação] não constitui [argumento] a favor daqueles [oponentes] - [696] por causa de uma falácia de composição e de divisão e

${ }_{161} \mathrm{Cf}$. , no original, a expressão "in illo et pro illo nunc pro quo". N. do T.

162 Cf. Duns Scotus, Lectura I, d. 40, q. un., n. 4-10 (XVII 511-513); Ordinatio I, d. 40, q. un. n. 4-10 (VI 310-313).

${ }^{163}$ A saber, a determinação da vontade como volição ou decisão atual. N. do T.

$164 \mathrm{Cf}$. acima n. 1.

165 Cf. Duns Scotus, Lectura II, d. 25, q. un., n. 94 (XIX 261): “(...) fica evidente que a potência racional é de si indeterminada para opostos, e por isso mesmo é determinada a um pela vontade, porque a potência racional (enquanto ciência) indiferentemente se relaciona com os opostos, e tampouco está em seu poder mais um do que o outro"; Rep. II, d. 25, q. un., n. [23] (ed. Vivès XXIII 129).

166 Cf., no original, a expressão "propositio de possibili". N. do T.

167 Cf. Duns Scotus, Ordinatio II, d. 5, q. 2 n. [7] (ed. Vivès XII 317).

168 Cf. Thomas, Summa theol. II-II, q. 49, a. 6 in corp. (VIII 371ab): "Semelhantemente, ademais, as coisas que são presentes, enquanto desse tipo, têm uma determinada necessidade: é necessário, pois, que Sócrates esteja sentado enquanto está sentado". Henricus Gand., Quodl. XI, q. 6, in corp. (f. 458L) e Rogerus Marston, De an. q. 10 ad 15 (BFS VII 434. 452), refutam, entretanto, o argumento de Tomás de Aquino.

${ }^{169}$ Aristot., De interpr. I, c. 9 (AL II1 17; c. 9, 19a23-24); cf. acima n. 59.

170 Cf. Duns Scotus, Lectura I, d. 39, q. 1-5, n. 58 (XVII 499); Ordinatio II, d. 1, q. 3, n. 158 (VII 79-80); Ordinatio III, d. 18, q. un., ad 4 n. [17] (ed. Vivès XIV 693a), onde Scotus explicou esta autoridade de Aristóteles.

171 Cf. novamente, no original, a expressão "pro tunc". Cf. acima as notas 155 e 156. N. do T. 
[por causa de uma falácia] de modo qualificado e pura e simplesmente ${ }^{172}-$, isso seria prolixo explicar agora. ${ }^{173}$ [Segue-se uma anotação interpolada: Quando algumas condições convêm à coisa sob uma razão determinada, e não absolutamente, em relação àquela razão as condições são verificadas ditas absolutamente ou não absolutamente da mesma coisa. Mas, 'contingência e necessidade' convêm tãosomente à coisa sob uma razão enquanto a coisa existe. Portanto, é na relação com a existência que aquelas condições são ditas da coisa mesma. Portanto, se a coisa, quando ela existe, é dita necessária ou contingente, também absolutamente ela deve ser dita necessária ou contingente; portanto, etc.].

65. Pode ser dito de outro modo que a vontade, quando está em alguma volição, então está naquela [volição] contingentemente, e aquela volição então ${ }^{174}$ se dá por ela mesma ${ }^{175}$ contingentemente; a não ser, pois, que então [a vontade se faça assim], jamais [assim se dará], porque jamais é de si mesma em outra ocasião. E assim como aquela [potência] se dá contingentemente [na volição], desse modo a vontade, então, é uma potência que tem poder com respeito ao oposto; e no 'então', ${ }^{176}$ em sentido de divisão. Não, a saber, que ela possa pôr [em ato] aquele oposto ao mesmo tempo com esse [outro], mas que tem poder de pôr aquele oposto neste instante, não pondo [então] aquele outro neste instante; [conclui-se] que põe o outro neste instante divisivamente, ${ }^{177}$ e isto não necessariamente, mas contingentemente.

66. Quando ao segundo [argumento contrário], ${ }^{178}$ se é argumentado sobre a vontade ${ }^{179}$ digo que aquela tem poder para 0 ato, não numa determinação ao ato inteligida nela mesma previamente, de modo que a primeira determinação, tanto no tempo quanto na natureza, ocorre na posição $0^{180}$ do ato. E se, então, toma-se sobre a mesma que 'para nada ela tem poder a não ser que anteriormente determinada', [isso] é falso.

67. Se, porém, argumenta-se sobre o intelecto que conhece opostos, então é verdade que, com respeito a algo extrínseco, ele não tem poder de algo a não ser que seja

172 Cf., no original, "et [fallaciam] secundum quid et simpliciter". Dito de maneira elementar, dá-se uma falácia deste gênero quando um termo, usado de modo limitado ou qualificado ("secundum quid") numa proposição antecedente, vem a ser usado em sentido ilimitado ou absoluto ("simpliciter") numa proposição conseqüente, tal como no seguinte exemplo recorrente: "O etíope é branco no que diz respeito aos seus dentes; logo, ele é branco". No texto scotista em questão, isso se dá, a saber, argumentando assim: 'é necessário que algum efeito causado pela vontade exista, se uma volição em ato é causada, logo é necessário que uma volição em ato exista'. N. do T.

$173 \mathrm{Cf}$. acima n. 3.

174 Isto é, "naquele instante de tempo em que é"; cf., no original, a expressão "tunc". N. do T.

175 Isto é, pela vontade. N. do T.

176 Cf., no original, a expressão "pro tunc"; cf. as notas 156 e 171. N. do T.

177 Cf., no original, a expressão "divisim". N. do T.

178 Cf. Godefridus de Font., Quodl. VIII q. 16 in corp. (PhB IV 151ss.); Quodl. X, q. 13 in corp. (PhB IV 374-376).

$179 \mathrm{Cf}$. a nota precedente.

180 Cf., no original, "in positio", ou seja, "no pôr" ou "no posicionar" o ato. N. do T. Cf. também C. González Ayesta, in: Juan Duns Escoto, op. cit., p. 71: "(...), de manera que la primera determinación, tanto en el orden cronológico como por naturaleza, es la posición del acto". 
determinado [697] de outra parte, porque a partir de si é daqueles [opostos] pelo modo da natureza, não tendo poder de se determinar a um [dos opostos]; logo, ele ou atuará sobre ambos, ou nada [atuará]. E se do intelecto for concluído que ele não é suficientemente uma potência racional, conceda-se de acordo com o que foi dito anteriormente. Do contrário, se - por impossibilidade --somente existisse [o intelecto] com as virtudes inferiores, sem a vontade, nada jamais se faria a não ser determinadamente, pelo modo da natureza, e não haveria nenhuma potência suficiente para fazer um ou outro de [efeitos] opostos.

68. Quanto ao terceiro [argumento contrário], ${ }^{181}$ diz-se que [a vontade] pode ter um ato acerca daqueles opostos que estão sob o seu primeiro objeto, [objeto] esse que, quanto ao ato de querer, é considerado [ser] o bem, verdadeiro ou aparente; [o ato da vontade], porém, não é acerca do oposto do seu primeiro objeto, [oposto esse] que é considerado [ser] o mal enquanto mal. Semelhantemente, dos atos [da vontade] é posto que ela tem poder para opostos, a saber, querer e desquerer, [isto é] acerca daquele [objeto] no qual pode ser encontrado algo da razão do primeiro objeto de ambos os atos, a saber, algo do bem e algo do mal. No fim último, [porém], nada do mal é encontrado, e com respeito a ele alguns ${ }^{182}$ parecem considerar que [a vontade] não seja [mais] uma potência racional. Semelhantemente, parecem pôr que, por algum hábito, [a vontade] possa ser imobilizada com respeito a alguns [itens finais] diferentes do fim último. Eu omito aqui a inquirição sobre a discussão desses ${ }^{183}$ tanto se acerca do fim [a vontade] é determinada para o querer, quanto se acerca do mal enquanto mal [ela é determinada] ao desquerer.

69. Quanto ao quarto ${ }^{184}$ argumento [contrário], sobre o sol, fica evidente acima, na resposta ao primeiro [item] objetado ${ }^{185}$ contra [a via de] Aristóteles.

[698] 70. Quanto ao quinto ${ }^{186}$ [argumento contrário], ${ }^{187}$ pode ser dito, de acordo com o princípio do primeiro artigo, ${ }^{188}$ que o frio jamais é producente do ser do calor; contudo, ele faz algo que, uma vez feito, algum outro [agente] pode aquecer mais, como, por exemplo, ele contrai para que o calor interior não seja dissipado, e dessa maneira o calor, comprimido, mais aqueça.

181 Cf. acima n. 4.

182 Cf. Thomas, Summa theol. I, q. 82, a. 1 in corp. (V 293a); Aegidius Rom., Quodl. III, q. 15 (f. 37vb-38rb); Godefridus de Font., Quodl. VI, q. 1 in corp. (PhB III 105ss); q. 7 in corp. (PhB III 158-164); q. 6 in corp. (PhB III 147-148); VIII q. 16 (PhB IV 162-172); Henricus Gand., Quodl. XII, q. 26 in corp. (AMPh s. 2, XVI 151-152), mas ver também Quodl. IX, q. 5 in corp. (AMPh s. 2, XIII 135-136).

183 Cf. Duns Scotus, Ordinatio I, d. 1, p. 2, q. 2, n. 82-158 (II 62-108); IV, d. 49, q. 9-10 (ed. Vivès XXI 316-388).

$184 \mathrm{Cf}$. acima n. 5 .

185 Cf. acima n. 43.

${ }^{186} \mathrm{Na}$ verdade, resposta ao sexto argumento contrário; cf. a nota seguinte. N. do T.

$187 \mathrm{Cf}$ acima n. 7.

188 Cf. acima n. 10-19. 
71. Sobre a projeção da bola, ${ }^{189}$ ainda que haja alguma contrariedade no movimento reflexo com respeito ao movimento reto quanto ao local que se requer entre os termos [de início e de fim] ${ }^{190}$ do movimento local, não há, contudo, contrariedade formal, porque o que move violentamente algo para algum lugar, move para todo lugar possível que é adquirido por meio daquele movimento. Se pode [movê-lo] diretamente para frente, assim é movido; se não [o pode], retorna, e isto terá sido feito pelo tempo em que o movimento [for] proporcionado à violência do movente.

72. Esta e outras coisas contingentes quaisquer, nos raios refletidos e refratados - e também noutros lugares -, não põem numa potência irracional nenhuma indiferença do tipo que há numa [potência] racional.

73. Quanto ao último [argumento contrário]:191 sem exceção, todas as potências passivas de si são de contradição. Ainda que, se a forma [fosse] ente necessariamente [como no caso dos corpos celestes], ${ }^{192}$ [tal que ela, então], necessariamente dependeria da matéria, o composto [de forma e matéria] seria incorruptível, e a matéria seria necessariamente sob aquele ato; mas, ela não [o seria] por uma necessidade da parte de si, mas [da parte] da forma. [Potências] ativas, entretanto, são de contradição, assim como expõe Aristóteles, por outro [aspecto]: [podem] 'ser e não' [ser]. ${ }^{193}$ Pois, se [isso] for inteligido do passivo de ação aproximado e não aproximado [ao agente], nesse caso toda [potência] ativa, cuja ação depende de um passivo de ação, pode ser de contradição, não a partir de si, mas de outra parte. Se [699] [isso] for entendido do que impede [o agente], nesse caso toda [potência] ativa natural corruptível é impedível, também por uma outra causa natural ativa. Mas, nenhuma [potência] natural [ativa] tem a partir de si poder de produzir ações opostas acerca do mesmo, ou [então] a partir de si [poder de] agir e não agir, no modo como uma potência racional é de contrariedade ${ }^{194}$ ou de contradição. ${ }^{195}$ Por isso mesmo, aquela proposição ${ }^{196}$ não se faz contra a intenção de Aristóteles, no que ele assinala a diferença anteriormente mencionada [entre potência racional e potência irracional]. ${ }^{197}$

189 Cf. acima n. 7.

190 Aqui, retomou-se os textos no códice A.

${ }^{191} \mathrm{Na}$ verdade, quanto ao penúltimo [ou quinto], cf. acima n. 6.

192 Aqui, sigo basicamente A. B. Wolter, Translation, in: John Duns Scotus, op. cit., p. 397: "(...) if the form were a necessary being [as in the case of the heavenly bodies], (...)". N. do T.

193 Cf. Aristot., Metaph. IX, t. 10 (AL XXV33 190; @ c. 5, 1050b10-11): "Logo, o que [é] possível ser pode ser e [também] não ser".

$194 \mathrm{Cf}$., no original, a expressão "potentia rationalis est contrarietatis". Isto é, tem liberdade de contrariedade, de agir deste modo ou daquele, tal como quando é dito que a vontade tem poder para querer $A$ ou $\neg A$. N. do T.

195 Cf., no original, a expressão "vel contradictionis". Isto é, tem liberdade de contradição, de agir ou não agir, ali onde isso é entendido, no caso da vontade, como tendo o poder de querer $A$ ou de não-querer (deixar de querer) A. N. do T.

${ }^{196}$ A saber, 'toda potência é de contradição'.

197 Cf. acima n. 1. 